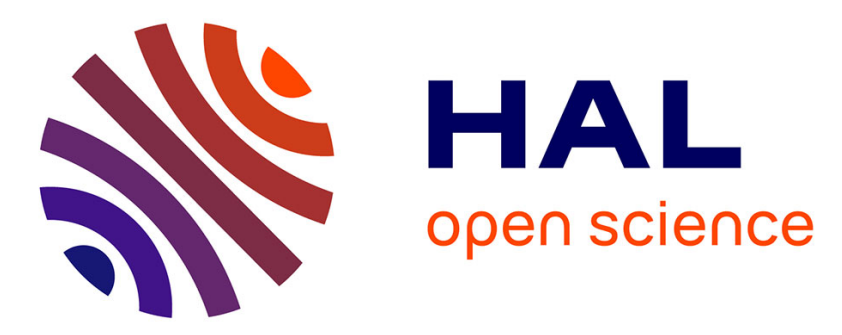

\title{
A thioglycerol route to bio-based bis-cyclic carbonates: poly(hydroxyurethane) preparation and post-functionalization
}

Oceane Lamarzelle, Geoffrey Hibert, Etienne Grau, Sébastien Lecommandoux, Henri Cramail

\section{To cite this version:}

Oceane Lamarzelle, Geoffrey Hibert, Etienne Grau, Sébastien Lecommandoux, Henri Cramail. A thioglycerol route to bio-based bis-cyclic carbonates: poly(hydroxyurethane) preparation and postfunctionalization. Polymer Chemistry, 2017, 8 (22), pp.3438 - 3447. 10.1039/c7py00556c . hal01611121

\section{HAL Id: hal-01611121 \\ https://hal.science/hal-01611121}

Submitted on 20 Nov 2019

HAL is a multi-disciplinary open access archive for the deposit and dissemination of scientific research documents, whether they are published or not. The documents may come from teaching and research institutions in France or abroad, or from public or private research centers.
L'archive ouverte pluridisciplinaire HAL, est destinée au dépôt et à la diffusion de documents scientifiques de niveau recherche, publiés ou non, émanant des établissements d'enseignement et de recherche français ou étrangers, des laboratoires publics ou privés. 


\title{
Thioglycerol route to bio-based bis-cyclic carbonates: Poly(hydroxyurethane) preparation and post-functionalization
}

\author{
Océane Lamarzelle ${ }^{a, b}$, Geoffrey Hibert ${ }^{a, b}$, Etienne Grau ${ }^{a, b^{*}}$, Sébastien Lecommandoux ${ }^{a, b^{*}}$ and \\ Henri Cramail $a, b^{*}$
}

\begin{abstract}
The present work is dedicated to the design of novel sulfur-substituted cyclic carbonates from thioglycerol, fatty acids and sugar derivatives. In this methodology, a sulfur atom is inserted in $\beta$ position of 5 -membered ring cyclic carbonates via a two-step synthesis including the thiol-ene coupling of thioglycerol on fatty acid derivatives, followed by a transcarbonation. A similar strategy was adopted to prepare glycolipid-based cyclic carbonates in order to bring biodegradability to the final poly(hydroxyurethane)s. The so-formed monomers were characterized by NMR spectroscopies, HPLC and DSC. The enhanced reactivity of sulfur-substituted cyclic carbonate was demonstrated through ${ }^{1} \mathrm{H}$ NMR spectroscopy kinetic study of a model reaction with hexylamine. Fatty acid- and glycolipid-based sulfursubstituted bis cyclic carbonates were then polymerized with diamines in solvent using a catalyst-free process. FTIR, NMR, SEC, DSC and TGA were performed to investigate the PHUs chemical structure, molar masses and thermal properties. Finally, the so-formed PHUs were post-functionalized by sulfonation with m-CPBA in order to tune the PHU properties. The impact of these chemical modifications was mostly studied on the polymer solubility and thermal stability.
\end{abstract}

\section{Introduction}

Since the new REACH regulation was edited few years ago, research groups and industries were asked to replace hazardous chemicals and harsh reaction conditions by greener intermediates and processes. Polyurethane markets were directly affected as toxic isocyanates and phosgene were involved in the synthesis of such polymers. In agreement with the legislation and the Green Chemistry principles, Non Isocyanate Polyurethanes (NIPUs) have attracted interest within the last decades for the replacement of classical PUs. ${ }^{1-3}$ Among the possible routes leading to isocyanate- and phosgene-free $\mathrm{PU}$, the most studied and promising solution to synthesize sustainable polyurethanes is the polyaddition between poly(cyclic carbonate)s and polyamines leading to poly(hydroxyurethane)s (PHUs). Contrary to the mature technologies applied for classical PU synthesis, ${ }^{4}$ PHU preparation still requires efforts to be industrialized. Indeed, the polymerization rate is not enough competitive in comparison to the reaction time required for many industrial processes. The conversions are generally incomplete, leading to residual monomers within the materials and lessened properties. This feature has been attributed to the low reactivity of 5-membered ring cyclic carbonates towards amines, coming from the high stability of such compounds. To tackle this issue, 6-, 7- and 8-membered ring cyclic carbonates, displaying a higher ring strain have demonstrated a significant increase of the polymerization rate when their polymerizations with diamines were performed. ${ }^{5-8}$ Unfortunately, most of the cyclic carbonates with larger ring size were not easy to handle at the industrial level due to their low stability at room temperature. In order to decrease the cyclic carbonate

a. Université de Bordeaux, LCPO, UMR 5629, F-33600, Pessac, France

b. CNRS, LCPO, UMR 5629, F-33600, Pessac, France

c. ITERG, F-33600, Pessac, France

+ Electronic Supplementary Information (ESI) available: [Experimental, Material and Methods, NMR, HPLC, DSC, TGA]. See DOI: 10.1039/x0xx00000x stability and subsequently favor the amine addition, an alternative strategy consisting in the insertion of electronwithdrawing groups nearby the 5-membered cyclic carbonate was carried out by several research groups. ${ }^{9-12}$ Another solution is the use of metal catalysts or organo-catalysts such as TBD, DBU or thioureas ${ }^{13,14}$ in order to increase the carbonyl electrophilicity of the cyclic carbonate and/or the nucleophilicity of the amine.

In agreement with a sustainable development, numerous research teams achieved the synthesis of green and bio-based plastics. ${ }^{15}$ Various studies reported the preparation of fatty acid-based cyclic carbonates as precursors for further PHU syntheses. ${ }^{16-21}$ Nonetheless, glycolipids 22,23 which result from the combination between sugar and fatty acids have not been used as starting material for cyclic carbonate and PHU preparations yet. Within the past few years, our group has been developing several generations of fatty acid-based cyclic carbonates starting from the synthesis of 5-membered cyclic carbonate obtained via epoxidation/carbonation of carboncarbon double bonds. ${ }^{16,24}$ The laborious preparation of 6 membered fatty acid-based cyclic carbonates was also investigated. ${ }^{5}$ More recently, we designed reactive 5membered ring cyclic carbonates, presenting ether and ester functions in $\beta$ position of the cycle, from glycerol and fatty acid derivatives. Nonetheless, ester moiety was sensitive to side reactions and impacted the resulting PHU molar masses and properties. Herein, the present work aims at designing other reactive cyclic carbonates by inserting a thioether function in $\beta$ position nearby the carbonate ring, taking advantage of the inertness of this function as well as the possibility to oxidize it after polymerization. Only few works already reported the synthesis of sulfur-based cyclic carbonates towards PHU syntheses. ${ }^{5-7,25,26}$ Among the reviewed carbonates, only one research team synthesized bis cyclic carbonates displaying a sulfur atom in $\beta$ position nearby the carbonate by reacting a tosylated glycerol carbonate with several dithiols. ${ }^{25}$

Hence, a new route towards sulfur-substituted cyclic carbonates has been set up via the thiol-ene coupling of 
thioglycerol (derived from glycerol) with bio-based derivatives, followed by a transcarbonation of the resulting diols using dimethyl carbonate (DMC). Following this strategy various fatty acid- and glycolipid-based cyclic carbonates were synthesized in order to tune the properties taking for instance, advantage of the biodegradability of glycolipids. Indeed, sugarbased polymers were shown to be biodegradable due to the occurrence of ester linkages within the backbone. ${ }^{27,28}$ After kinetic investigations on model compound aminolysis, a large range of PHUs was synthesized from the prepared bis cyclic carbonates and commercial diamines. Structural and thermal properties were examined by $1 \mathrm{D}$ and $2 \mathrm{D}$ NMR techniques, SEC, TGA and DSC. Taking advantage of the sulfur content within the PHU backbones, thioether sulfonation was finally carried out on two PHU in order to study the effect of sulfur oxidation state on material properties.

\section{Cyclic carbonate synthesis}

Two families of sulfur-substituted bis-cyclic carbonates have been design from (i) fatty acid derivatives and (ii) from trehalose and fatty acid methyl esters. The first family involves a prior dimerization of fatty acid derivatives before processing to the thiol-ene coupling with thioglycerol. However, due to the presence of numerous hydroxyl functions onto the trehalose, the formation of glycolipid-based cyclic carbonate by transcarbonation with DMC was conducted prior to the transesterification between sugar and fatty acid derivative.

The synthesis of fatty acid-based cyclic carbonates was first carried out following a three-step synthesis described in Scheme 1. In order to design bifunctional monomers with tunable properties, undecenoic and oleic acid derivatives were first coupled via transesterification or etherification depending on the central building block desired. Thus, Und(ester)-diene was synthesized by transesterification between methyl-10undecenoate and 10-undecen-1-ol with TBD as catalyst. Besides, Und(ether)-diene and Oleyl(ether)-diene were prepared by etherification of respectively 1-bromo-10undecene with 10-undecen-1-ol and oleyl methanesulfonate with oleyl alcohol.(Scheme 1, ESI Figure 8).

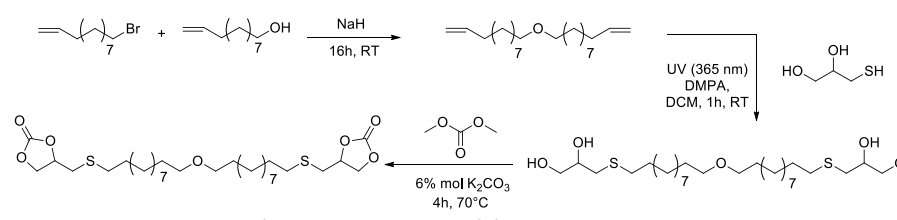

Scheme 1 - Strategy for the synthesis of fatty acid-based cyclic carbonates (here Und(ether)-bCC).

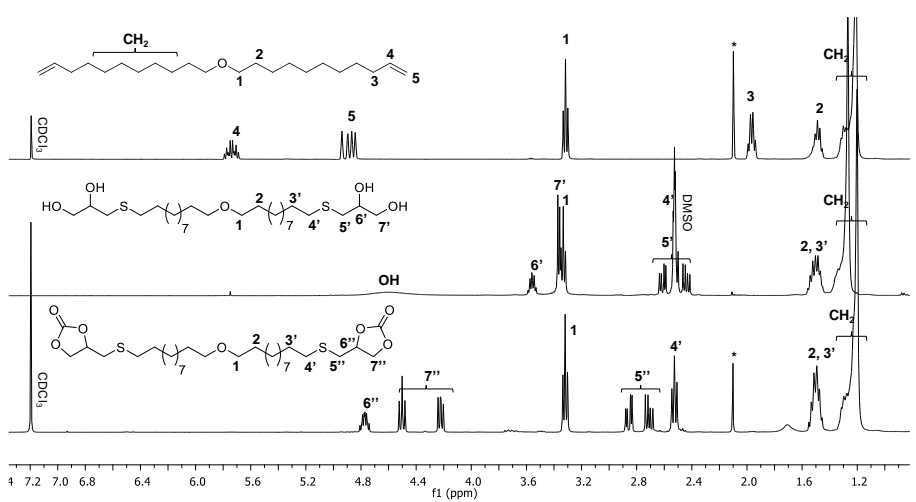

Figure 1 - Stacked ${ }^{1} \mathrm{H}$ NMR spectra of (1) Und(ether)-diene in $\mathrm{CDCl}_{3}$ (2) Und(ether)-tetraol in DMSO and (3) Und(ether)-bCC in $\mathrm{CDCl}_{3}$ (* impurities or solvent traces).

The conversions were followed by proton NMR with the disappearance of the protons nearby the alcohol as well as the bromo or mesyl functions. All the synthesized dienes were obtained pure after flash chromatography. Thiol-ene coupling was then conducted on the so-formed dienes with 2 eq. of thioglycerol in a UV reactor $(365 \mathrm{~nm})$ using DMPA as photoinitiator. The conversion of dienes was followed by ${ }^{1} \mathrm{H}$ NMR spectroscopy with the disappearance of the characteristic protons from the external and internal double bonds at respectively 4.96-5.73 ppm and $5.33 \mathrm{ppm}$ (Figure 1). The terminal unsaturated Und(ether)-diene and Und(ester)diene were completely converted into their corresponding tetraols after $1 \mathrm{~h}$ with $0.5 \mathrm{~mol} . \%$ of DMPA, and yielded at $99 \%$ after a washing procedure. Besides, the isomerization product resulting from the Markovnikov addition was detected by ${ }^{1} \mathrm{H}$ NMR for Und(ether)-tetraol with the characteristic $\mathrm{CH}_{3}$ doublet below 1 ppm (Figure 1).

With regard to the internal unsaturated Oleyl(ether)-diene, $90 \%$ conversion into the corresponding tetraol was reached after $48 \mathrm{~h}$ with higher amount of DMPA (1.5 mol.\%). Noteworthy, Meier and coll. ${ }^{29}$ and Li and coll. ${ }^{30}$ have already used this strategy for a $A_{2}$-type monomer synthesis from thioglycerol and methyl undecenoate that was used in selfpolycondensation to give linear or hyperbranched polymers. Lastly, the tetraol carbonation was performed in DMC as reactive solvent using $\mathrm{K}_{2} \mathrm{CO}_{3}$ as catalyst. This transcarbonation strategy using linear carbonates to produce cyclic carbonate moieties has been extensively employed. ${ }^{31-33}$ However, to the best of our knowledge, this is the first time that a cyclic carbonate, originated from thioglycerol, was synthesized using the transcarbonation pathway. The appearance of the multiplet at $4.8 \mathrm{ppm}$ and the triplets around 4.2-4.5 ppm confirmed the cyclic carbonate formation (Figure 1). The band obtained in FTIR measurement in the range 1795-1775 $\mathrm{cm}^{-1}$, corresponding to the carbonyl vibration of the cycle corroborated the ${ }^{1} \mathrm{H}$ NMR results. After $4 \mathrm{~h}$ reaction, almost full conversion was attained for all the fatty acid-based tetraols and the resulting bis-cyclic carbonates were purified. Purities, melting points and structure were analyzed via HPLC, DSC and several NMR techniques, respectively $\left({ }^{13} \mathrm{C} N M R,{ }^{1} \mathrm{H}-{ }^{1} \mathrm{H}\right.$ COSY NMR, ${ }^{1}{ }^{-13} \mathrm{C}$ HSQC; see ESI). While bringing flexibility with 
pendant chains to the central block, a low glass transition temperature of $-59^{\circ} \mathrm{C}$ was displayed by Oleyl(ether)-bcc. Nonetheless, no significant difference was observed between Und(ether)-bcC and Und(ester)-bcC melting temperatures $\left(T_{m}\right.$ of 93 and $89^{\circ} \mathrm{C}$ respectively).

The glycolipid-based bis cyclic carbonates were then prepared following the four-step synthesis depicted in Scheme 2. Contrarily to the lipidic-based ones, thiol-ene coupling of thioglycerol was carried out first on methyl undecenoate and methyl oleate due to the chemical sensitivity of sugar towards carbonation with DMC. According to ${ }^{1} \mathrm{H}$ NMR spectroscopy, full conversions of the double bonds were reached after respectively $2 \mathrm{~h}$ and $24 \mathrm{~h}$, the disparity coming from the difference in reactivity between terminal and internal double bonds. ${ }^{34}$ The so-formed diol esters were then purified and carbonated using the carbonation procedure previously mentioned. The carbonation was confirmed by ${ }^{1} \mathrm{H}$ NMR spectroscopy with the disappearance of the peak assigned to the protons nearby the diol $(3.7,3.5 \mathrm{ppm})$ and the appearance of the peaks corresponding to the carbonate (4.9-4.2 ppm).

The last step of this route was the chemical esterification of the primary alcohols of the trehalose, enabling to attach the lipidic-based cyclic carbonate to the sugar moiety. However, this reaction only proceeds on an acidic function and requires the hydrolysis of the methyl ester function of the so-formed purified lipidic carbonates. Noteworthy, the fatty acid methyl esters were chosen as starting reactants as no carbonate was obtained during the carbonation step in the presence of acidic moiety. This feature was explained by the reaction between the acidic function and $\mathrm{K}_{2} \mathrm{CO}_{3}$, which prevents the deprotonation of the hydroxyl groups and thus their carbonation with DMC. The intermediate hydrolysis step was thus performed in a water/acetone solution, using lipase B from Candida antarctica immobilized ion acrylic resin (also known as Novozyme 435) as a catalyst. The enzymatic hydrolysis was chosen compared to a classical way, using a strong base such as $\mathrm{KOH}$, to prevent the opening of the cyclic carbonate linked to the fatty chain. After $48 \mathrm{~h}$ stirring at $60^{\circ} \mathrm{C}$, the reaction mixture was filtrated to remove the enzyme and the acid was purified by flash chromatography to yield the fatty acid cyclic carbonate at $70 \%$. The hydrolysis was confirmed by means of ${ }^{1} \mathrm{H}$ NMR spectroscopy with the disappearance of the methyl ester peak at $3.6 \mathrm{ppm}$. There was no shift or disappearance of the peaks corresponding to the

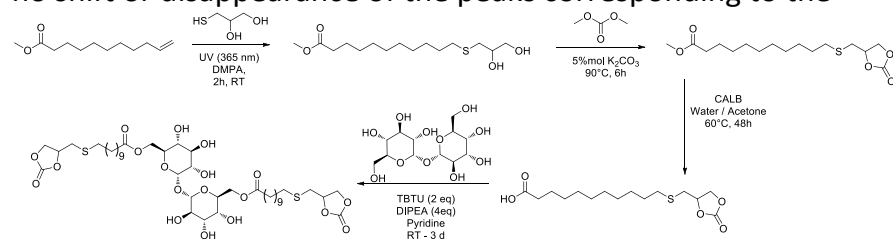

Scheme $\mathbf{2}$ - Strategy for the synthesis of glycolipid-based cyclic carbonates (here Trehal-Und-bCC).

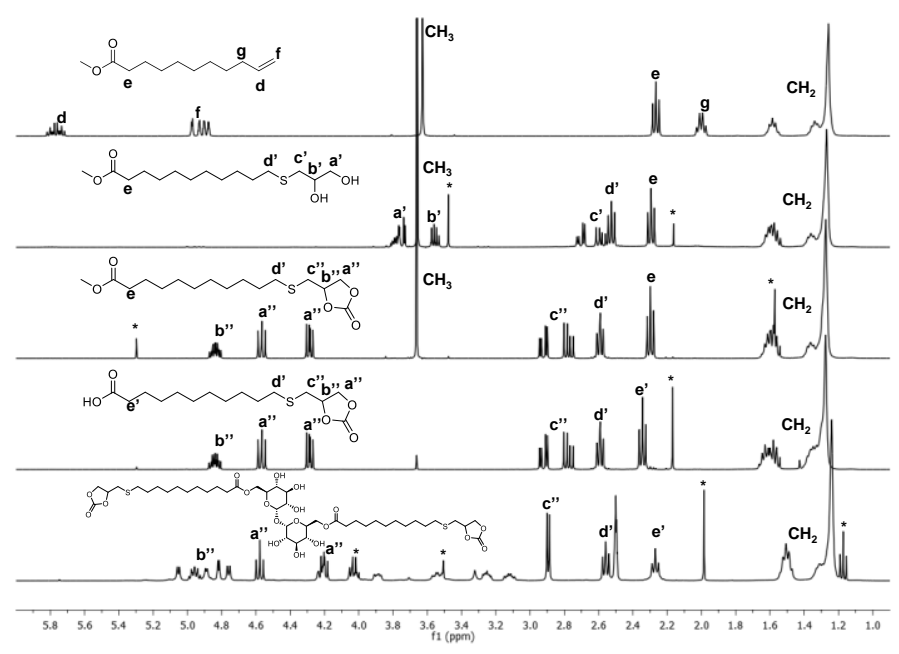

Figure 2 - Stacked ${ }^{1} \mathrm{H}$ NMR spectra of (1) Methyl undecenoate (2) MethylUnd-diol (3) Methyl-Und-CC, (4) Acid-Und-CC, and (5) Trehal-Und-bCC in $\mathrm{CDCl}_{3}$ (* Impurities or trace of solvents).

cyclic carbonate confirming its inertness in this step (Figure 2). The last reaction step leading to the formation of glycolipidbased bis cyclic carbonates is a two-step one-pot selective esterification of the primary alcohol developed by Grindley 35,36 that was applied to our system. The reaction conditions are reported on Scheme 2 and on ESI. The coupling between lipidic and trehalose parts was confirmed by the shift of the peaks of the protons nearby the primary alcool of trehalose: from 3.48 and 3.55 to 4.28 and $4.02 \mathrm{ppm}$ and from 3.65 to $3.89 \mathrm{ppm}$, respectively (Figure 2). Purities, melting points and structure of the so-formed and purified cyclic carbonates were analyzed via HPLC, DSC and several NMR techniques respectively $\left({ }^{13} \mathrm{C} N M R,{ }^{1} \mathrm{H}-{ }^{1} \mathrm{H}\right.$ COSY NMR, ${ }^{1} \mathrm{H}^{13} \mathrm{C} \mathrm{HSQC}$; see ESI). Using thioglycerol route, 5 different fully bio-based bis-cyclic carbonates were synthesized with high purity. To the best of our knowledge, this is the first time that the synthesis of biobased cyclic carbonates with a sulfur atom in $\beta$ position nearby the cycle was conducted using thiol-ene 'click' chemistry.

\section{Kinetic measurements}

As reported in the literature, ${ }^{9-12}$ the insertion of an heteroatom nearby a 5-membered ring cyclic carbonate confers to the latter a higher reactivity towards aminolysis. Nonetheless, this feature has not been investigated when a thioether function is placed nearby a cyclic carbonate. In order to quantify the thioether effect on cyclic carbonate aminolysis, a kinetic study of a model reaction was achieved. Hence, a sulfur-substituted mono-cyclic carbonate (Dec-CC-S) was

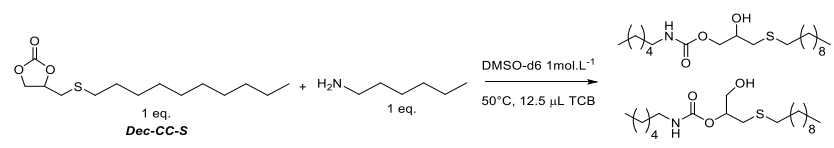

Scheme 3 - Model reaction of Dec-CC-S aminolysis with hexylamine in DMSO-d $\mathrm{d}^{6}\left(1 \mathrm{~mol} \cdot \mathrm{L}^{-1}\right)$ at $50^{\circ} \mathrm{C}$. 


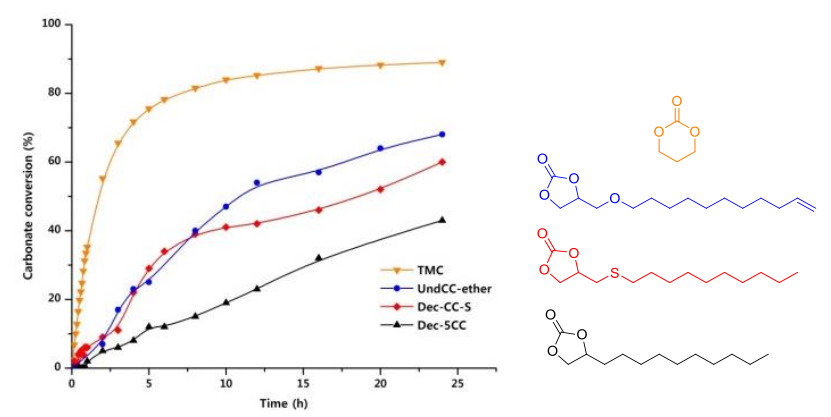

Figure 3 - Kinetic of the model reactions of several cyclic carbonates with hexylamine followed by ${ }^{1} \mathrm{H}$ NMR spectroscopy. $\left(50^{\circ} \mathrm{C}, 1 \mathrm{~mol} . \mathrm{L}^{-1}\right.$ in DMSO-d ${ }^{6}$, ratio $1: 1)$

synthesized via the thiol-ene coupling of thioglycerol and 1decene followed by carbonation with DMC (ESI). Dec-CC-S was then reacted with hexylamine in DMSO- $\mathrm{d}^{6}$ and the model reaction was monitored in situ by ${ }^{1} \mathrm{H}$ NMR for 2 days at $50^{\circ} \mathrm{C}$. Trichlorobenzene (TCB) was injected in the NMR tube as external reference (Scheme 3).

The cyclic carbonate conversions were calculated following the disappearance of the multiplet at $4.8 \mathrm{ppm}$ and were reported on a graph showing the conversion of Dec-CC-S as a function of time (Figure 3). Sulfur-substituted cyclic carbonate was compared to trimethylene carbonate (TMC) and to an aliphatic-substituted cyclic carbonate (Dec-5CC), known to be respectively highly and poorly reactive towards aminolysis. Kinetic results showed an improved reactivity of sulfur-based

Table 1 - Kinetic, selectivity and DFT data for ether- and sulfur-substituted mono cyclic carbonates.

\begin{tabular}{|c|c|c|}
\hline \multicolumn{3}{|c|}{ Kinetic and selectivity * } \\
\hline & UndCC-ether & Dec-CC-S \\
\hline Ratio urethane:urea & $97: 3$ & $94: 6$ \\
\hline $\mathrm{k}_{\text {app }}\left(\mathrm{L} . \mathrm{mol}^{-1} \cdot \mathrm{h}^{-1}\right)$ & 0.09 & 0.08 \\
\hline \multicolumn{3}{|c|}{ DFT Calculations } \\
\hline$-x$ & -OMe & -SMe \\
\hline \multicolumn{3}{|l|}{ Bond lengh $(\AA ̊)$} \\
\hline $\int_{0} \leq x^{x}$ & 1.358 & 1.359 \\
\hline \multicolumn{3}{|l|}{ Bond lengh $(\AA ̊)$} \\
\hline & 1.363 & 1.362 \\
\hline \multicolumn{3}{|l|}{$\Delta \mathrm{H}_{\mathrm{f}}\left(\mathrm{kJ} \cdot \mathrm{mol}^{-1}\right)$} \\
\hline & -27.36 & -26.19 \\
\hline \multicolumn{3}{|l|}{$\Delta \mathrm{H}_{\mathrm{f}}\left(\mathrm{kJ}^{-} \mathrm{mol}^{-1}\right)$} \\
\hline & -55.90 & -53.76 \\
\hline
\end{tabular}

cyclic carbonate towards hexylamine in comparison with Dec5CC. Additionally, Dec-CC-S displayed a similar reactivity than UndCC-ether which is an ether-substituted cyclic carbonate already reported by our group 11 to be reactive towards aminolysis. The comparable reactivity was confirmed by the DFT calculations (Table 1) showing an enthalpy of hydroxyurethane formation $\Delta \mathrm{H}_{\mathrm{f}}=-53.76 \mathrm{~kJ} . \mathrm{mol}^{-1}$ close to the one calculated for ether-substituted cyclic carbonate. The $k_{a p p}$ were then calculated upon the 6 first hours from the kinetic results assuming $2^{\text {nd }}$ law order kinectics. Dec-CC-S exhibited a $\mathrm{k}_{\mathrm{app}}=0.08 \mathrm{~L} \cdot \mathrm{mol}^{-1} \cdot \mathrm{h}^{-1}$ in the same range than UndCC-ether $k_{\text {app }}$ (0.09 L. $\mathrm{mol}^{-1} \cdot \mathrm{h}^{-1}$, see Table 1 ).

Additionally, as already reported in the literature, ${ }^{11,16}$ side reactions could occur during the aminolysis. It is known that primary amines can react with urethane functions leading to urea formation. Signals from the labile proton of urea function were detected by ${ }^{1} \mathrm{H}$ NMR with the shift of the labile proton at $6.8 \mathrm{ppm}$. The proportion between urea and urethane formed during the model reaction could be evaluated at $6 \%$ for the sulfur-substituted cyclic carbonate at $50 \%$ of conversion and was equivalent to the one obtained for the ether-substituted cyclic carbonate.

\section{Poly(hydroxyurethane)s synthesis and characterization}

The polyadditions of the sulfur-substituted bis-cyclic carbonates (Figure 4) with 1,10-diaminodecane (10DA), isophorone diamine (IPDA) and Priamine ${ }^{\circledR} 1075$ from CRODA as comonomers were carried out in order to investigate the relation between monomer structures and poly(hydroxyurethane)s (PHU) properties.

The polymerizations were performed in DMF at $1 \mathrm{~mol}^{-\mathrm{L}^{-1}}$ and $70^{\circ} \mathrm{C}$ under nitrogen atmosphere without any catalyst. The thermoplastic PHUs obtained were further characterized by ${ }^{1} \mathrm{H}$ NMR, SEC, DSC and TGA without prior quenching and precipitation after 7 days. All the data are reported in Table 2. PHUs formation was followed by ${ }^{1} \mathrm{H}$ NMR with the disappearance of the signals in $\alpha$-position nearby the cycle in the ranges 4.2-4.6 ppm, and with the presence of the characteristic protons nearby the nitrogen atom of the urethane linkage at $2.98 \mathrm{ppm}$ (Figure 5 and ESI Figure 10). The conversions were determined after $24 \mathrm{~h}$ and 7 days of polymerization in order to confirm that polyadditions occur within the first hours of reaction as demonstrated in previous works. ${ }^{11}$ The carbonate consumption was also confirmed by FTIR spectroscopy with the disappearance of the carbonate band at $1800 \mathrm{~cm}^{-1}$ and the appearance of bands at 1680 and $1530 \mathrm{~cm}^{-1}$, which correspond respectively to $\mathrm{C}=\mathrm{O}$ and $\mathrm{NH}$ vibrations of the urethane function.

Generally, the calculated carbonate conversions from ${ }^{1} \mathrm{H}$ NMR spectroscopy were found not total (around 93\%) and similar after $24 \mathrm{~h}$ or 7 days of polymerization. Besides, the trehalosebased cyclic carbonates displayed lower conversions, around 


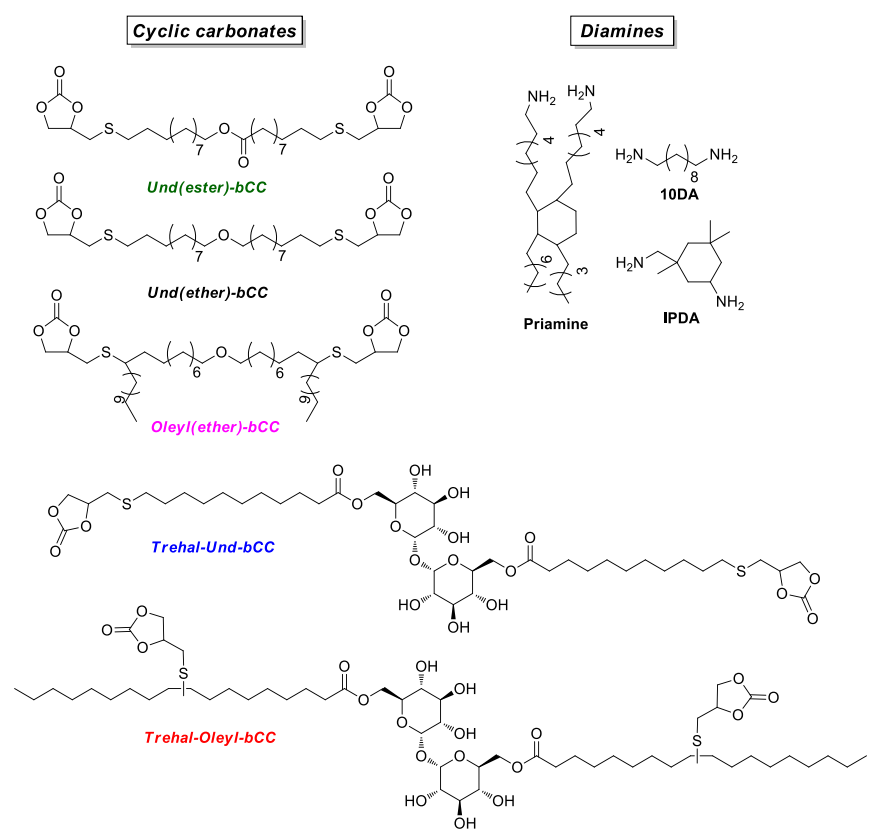

Figure 4- Panel of monomers used for the preparation of poly(hydroxyurethane)s

80-90\% (PHU 7 and 9), in comparison with the fatty acid-based ones (PHU 1 and 5). This feature could be interpreted by binding of the trehalose moieties present in PHU $\mathbf{7}$ and $\mathbf{9}$ with solvent and monomers via weak interactions, limiting the monomer diffusion inside the polymerization system. Additionally, the lowest conversion of $73 \%$ was exhibited by PHU 10, resulting from the polymerization between a trehalose-based cyclic carbonates and the less reactive IPDA.

As discussed in the kinetic part, side reactions could occur during the polymerization to form urea moieties that were identified by proton NMR with the shift of the labile proton at $6.8 \mathrm{ppm}$. The proportion between urea and urethane formed during the polymerization could be evaluated and were similar $(2-11 \%)$ than in previous model reaction. It is also known that primary amines could react with ester functions to form amide linkages. However, amide functions characterized by the labile proton at $7.6 \mathrm{ppm}$ were not detected for ester-containing polymers.

SEC of the PHUs was performed in DMF ( $\mathrm{LiBr}$, PS standards) except for Priamine-based PHUs where THF (PS standards) was used. Molar masses ranging from 2800 to 14900 g. mol ${ }^{-1}$ ( $Đ$ : 1.67-3.7) in DMF and from 6300 to 11700 g. mol-1 (Đ: 2.052.15) in THF were obtained after 7 days of polymerization. As shown on the SEC traces in Figure 6, PHU 7 and 8 synthesized from the Trehal-Und-bcC exhibit higher molar masses than PHU 9 and 10 obtained from the polymerization of TrehalOleyl-bCc, probably due to the lower reactivity of the oleic acid-based cyclic carbonate. Besides, particularly low PHUs molar masses around 3000 g. $\mathrm{mol}^{-1}$ were obtained for both cyclic carbonate polymerizations when IPDA was used as

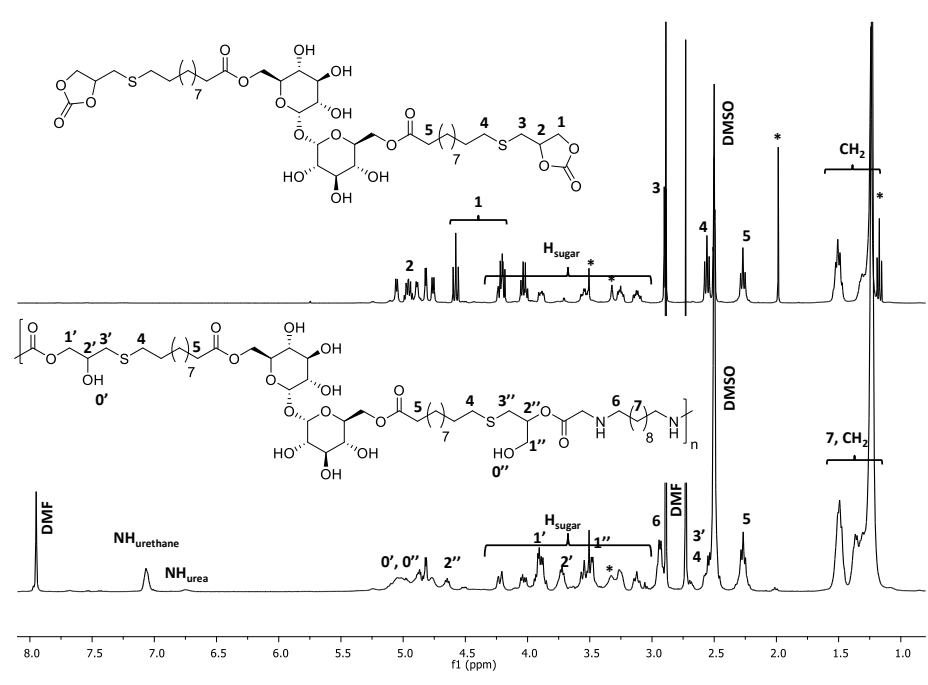

Figure 5- Stacked ${ }^{1} \mathrm{H}$ NMR spectra of (1) Trehal-Und-bCC and (2) PHU 7 in DMSO. (* residual monomers/chain ends/impurities)

comonomer. This feature could be related to the steric hindrance of the cyclic diamine and to the presence of one secondary amine function, preventing the efficient cyclic carbonate aminolysis.

Afterwards, the thermal properties of the synthesized PHUs were determined by DSC and TGA and were correlated to their chemical structures. A large panel of thermal behavior was obtained with $\mathrm{T}_{\mathrm{g}}$ ranging in between -34 and $56^{\circ} \mathrm{C}$ depending on the polymerized monomers. Amorphous PHUs were obtained with Oleyl(ether)-bCC as monomer due to the long alkyl dangling group imparted by the oleic part. Contrarily, PHU 8 and 10 displayed $\mathrm{T}_{\mathrm{g}}$ values of respectively $36^{\circ} \mathrm{C}$ and $56^{\circ} \mathrm{C}$ conferred by the rigid and cyclic IPDA. In a general trend, glycolipid-based PHUs exhibited higher $\mathrm{T}_{\mathrm{g}}$ than the fatty acidbased ones as the bicyclic trehalose moieties conferred also rigidity to the resulting materials (Figure 7). Some fatty-acidbased PHUs were semi- crystalline, thanks to the well-defined monomer structure with ether or ester linkages on the backbone that could form crystalline clusters by hydrogen bonding with pendant hydroxyl groups and urethane carbonyl moieties. However, in the case of PHU 1 and PHU 5, several melting peaks appeared revealing different crystallization modes or a possible segregation between soft and hard segments (Figure 7). Surprisingly, glycolipid-based PHUs were all amorphous materials. Indeed, as reported by Gross and coworkers, ${ }^{37}$ glycolipid monomers are able to bring crystallinity to polymers by sugar/sugar and lipid/lipid stackings. However, hydroxyurethane moieties within the PHU backbone can create weak interactions with hydroxyl functions of the trehalose and consequently hinder the formation of the above-mentioned stackings. This hypothesis still needs further investigations. 
Table 2 - Characterization of PHUs obtained from synthesized sulfur-substituted bis-cyclic carbonates and diamines.

$$
\text { (eq. }
$$

\begin{tabular}{|c|c|c|c|c|c|c|c|c|}
\hline PHU & Bis-CC & Diamine & $\begin{array}{l}\text { Conversion } \\
24 \mathrm{~h} / 7 \mathrm{~d}(\%)^{3}\end{array}$ & $\begin{array}{c}\text { Ratio Urea } \\
\text { /Amide/ } \\
\text { Urethane }^{1,2}\end{array}$ & $\begin{array}{c}\bar{M}_{\mathrm{n}}\left(\mathrm{g} \cdot \mathrm{mol}^{-1}\right) \\
{[\boxminus]^{1}}\end{array}$ & $\begin{array}{c}T_{g} \\
\left({ }^{\circ} \mathrm{C}\right)^{\mathrm{a}}\end{array}$ & $\begin{array}{c}\mathrm{T}_{\mathrm{m}} \\
\left({ }^{\circ} \mathrm{C}\right)^{\mathrm{a}}\end{array}$ & $\begin{array}{l}\mathrm{T}_{\mathrm{d} 5 \%} \\
\left({ }^{\circ} \mathrm{C}\right)^{\mathrm{b}}\end{array}$ \\
\hline 1 & \multirow{2}{*}{$\begin{array}{c}\text { Und(ether)- } \\
\text { bCC }\end{array}$} & 10DA & $93 / 99$ & $11 / 0 / 89$ & 10900 [1.79] & nd & $46 / 84 / 97$ & 273 \\
\hline 2 & & Priamine & $\mathrm{nd} / 93.5$ & nd & $8200[2.15]^{*}$ & nd & 50 & 268 \\
\hline 3 & \multirow{2}{*}{$\begin{array}{l}\text { Oleyl(ether)- } \\
\text { bcc }\end{array}$} & $10 \mathrm{DA}$ & nd & nd & 11900 [1.67] & -29 & - & 262 \\
\hline 4 & & Priamine & $90.5 / 92.5$ & nd & $11700[2.23]^{*}$ & -34 & - & 286 \\
\hline 5 & \multirow{2}{*}{$\begin{array}{c}\text { Und(ester)- } \\
\text { bCC }\end{array}$} & $10 \mathrm{DA}$ & $97.5 / 100$ & $10 / 0 / 90$ & $14900[1.86]$ & -8 & 72 & 258 \\
\hline 6 & & Priamine & $92.5 / 97.5$ & nd & $6300[2.05]^{*}$ & -26 & 33 & 258 \\
\hline 7 & \multirow{2}{*}{$\begin{array}{l}\text { Trehal-Und- } \\
\text { bCC }\end{array}$} & 10DA & $\mathrm{nd} / 92$ & $8 / \mathrm{nd} / 92$ & $10000[3.7]$ & 34 & - & 262 \\
\hline 8 & & IPDA & $\mathrm{nd} / 86$ & $9 / n d / 91$ & 3000 [3.4] & 36 & - & 253 \\
\hline 9 & \multirow{2}{*}{$\begin{array}{c}\text { Trehal-Oleyl- } \\
\text { bCC }\end{array}$} & $10 \mathrm{DA}$ & $\mathrm{nd} / 80$ & $2 / \mathrm{nd} / 98$ & 3200 [1.9] & 16 & - & 246 \\
\hline 10 & & IPDA & $\mathrm{nd} / 73$ & $7 / n d / 93$ & 2800 [1.9] & 56 & - & 240 \\
\hline
\end{tabular}

${ }^{1}$ : Determined at the end of the polymerization (7 days); SEC DMF (LiBr, PS Std); ${ }^{\text {: }}$ determined by SEC THF (PS Std); ${ }^{2}$ : Determined using the relations (E), ( $E^{\prime}$ ) and ( $\left.E^{\prime \prime}\right)$ (see ESI). ${ }^{3}$ : Conversions determined by ${ }^{1} \mathrm{H}$ NMR spectroscopy; ${ }^{a}$ : Determined by DSC at $10^{\circ} \mathrm{C} . \mathrm{min}^{-1}$ from the second cycle. ; ${ }^{b}$ : Determined by TGA at $10^{\circ} \mathrm{C}$. min $^{-1}$ under nitrogen.; nd : non-determined because of insolubility issues or shift overlaping.

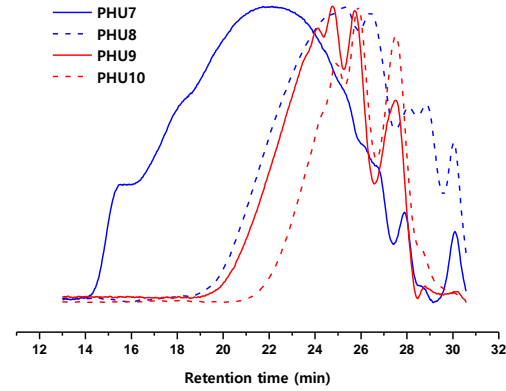

Figure 6- SEC chromatograms of PHU 7 to 10 (DMF, LiBr, PS standards, RI detector).

With regard to PHU thermal stability, 5 w.\% loss degradation temperatures in the range 240 to $286^{\circ} \mathrm{C}$ were measured and were homogeneous to literature results. ${ }^{1}$ PHU 4 made from monomers with aliphatic pendant chains exhibited the highest resistance to temperature with a $T_{d 5} \%$ of $286^{\circ} \mathrm{C}$. Besides, the Figure 7 indicates that glycolipid-based polymers degrade faster than lipidic-based ones, displaying lower $T_{d 5 \%}$. Nonetheless, residual carbon content ranging in between 10 and $20 \%$ was observed after $500{ }^{\circ} \mathrm{C}$ and was attributed to the degradation mode of trehalose.

\section{Thioether post-functionalization}

Taking advantage of the sulfur atoms contained in PHU backbones, a post-functionalization by selective oxidation of the thioether groups to sulfones was performed on PHU $\mathbf{5}$ and

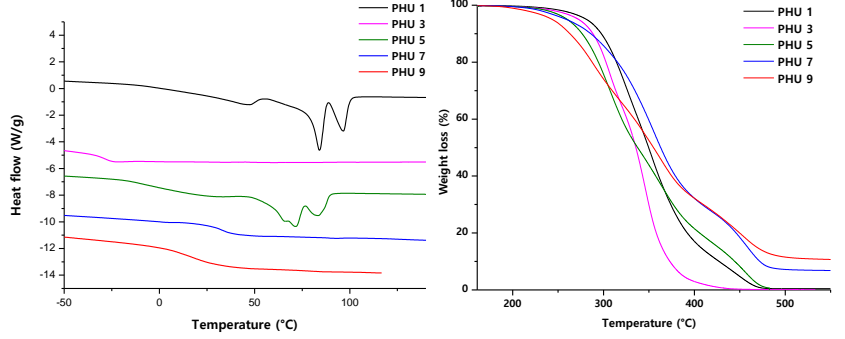

Figure 7 - DSC second heating cycles $\left(10^{\circ} \mathrm{C} / \mathrm{min}\right)$ of PHU 1, 3, 5, 7 and 9 and corresponding TGA traces from 160 to $550^{\circ} \mathrm{C}$ (after an isothermal procedure of $15 \mathrm{~min}$ at $160^{\circ} \mathrm{C}$ to remove the residual DMF).

PHU 7, in order to tune the final properties and to subsequently broaden applications.

The sulfonation (or sulfoxidation) of polymeric materials has already been described on linear fatty acid-based polymers 38,39 but has never been attempted on PHUs. In these studies, the thioether oxidation was reported to impact water solubility of the post-functionalized polymers as well as their thermal stability and crystallinity. As an example, Cadiz and coworkers 39 post-functionalized a fully bio-based triblock copolymer derived from PLA and castor oil derivatives that exhibited enhanced thermal stability and lower cristallinity. Hence, the sulfonation was carried out on PHU $\mathbf{5}\left(\bar{M}_{\mathrm{n}}=14900\right.$ g. $\left.\mathrm{mol}^{-1}, \ominus=1.86\right)$ and PHU $7\left(\bar{M}_{\mathrm{n}}=10000\right.$ g.mol-1, $\left.Ð=3.7\right)$ prepared by polyaddition of respectively Und(ester)-bCC and Trehal-Und-bcC with 10DA as comonomer. The postfunctionalized PHU 5-sulfone and PHU 7-sulfone were 


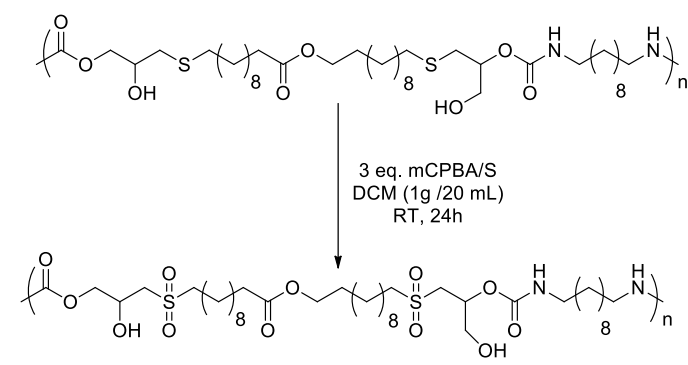

Scheme 4 - Experimental procedure for PHU 5 sulfonation

Table 3 - Characterization of PHU 5 and PHU 7, before and after sulfonation.

\begin{tabular}{|c|c|c|c|c|c|}
\hline PHU & bcc & $\begin{array}{c}\bar{M}_{\mathrm{n}}\left(\mathrm{g} \cdot \mathrm{mol}^{-1}\right) \\
{[\mathrm{E}]^{1}}\end{array}$ & $\begin{array}{c}\mathrm{T}_{\mathrm{g}} \\
\left({ }^{\circ} \mathrm{C}\right)^{\mathrm{a}}\end{array}$ & $\begin{array}{c}T_{f} \\
\left({ }^{\circ} \mathrm{C}\right)^{\mathrm{a}}\end{array}$ & $\begin{array}{l}T_{\mathrm{d} 5 \%} \\
\left({ }^{\circ} \mathrm{C}\right)^{\mathrm{b}} \\
\end{array}$ \\
\hline PHU 5 & Und(ester)- & $14900[1.86]$ & -8 & 72 & 258 \\
\hline $\begin{array}{l}\text { PHU 5- } \\
\text { sulfone }\end{array}$ & $b c c$ & 2900 [1.43] & 4 & 92 & 213 \\
\hline PHU 7 & Trehal-Und- & $10000[3.7]$ & 34 & - & 262 \\
\hline $\begin{array}{l}\text { PHU } 7 \text { - } \\
\text { sulfone }\end{array}$ & $b c c$ & $10900[3.8]$ & 52 & - & 219 \\
\hline
\end{tabular}

*UV detector used for SEC in DMF

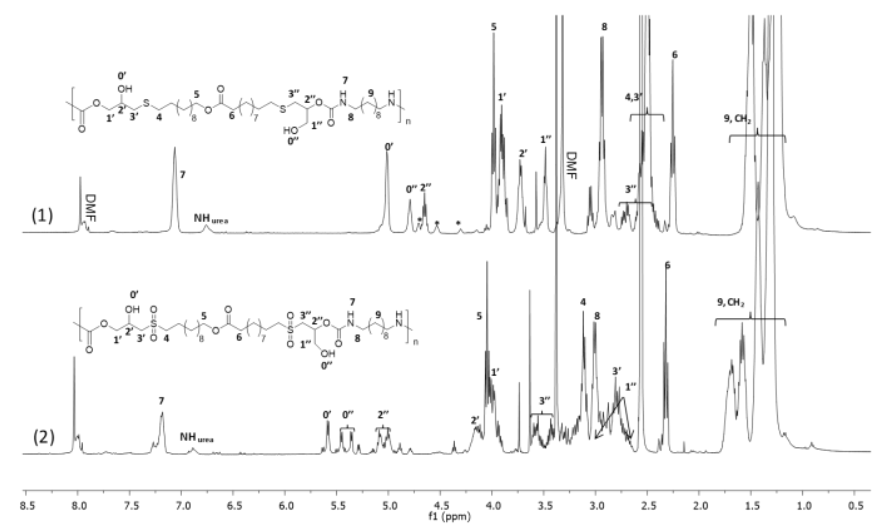

Figure 8- Stacked ${ }^{1} \mathrm{H}$ NMR spectra of (1) PHU 5 and (2) PHU 5-sulfone in DMSO-d6. (* residual monomers/chain ends).

analyzed either by NMR, DSC and TGA and the results are reported in Table 3.

The oxidation of PHU 5 into PHU 5-sulfone was carried out in $\mathrm{DCM}$ at room temperature in the presence of 3 eq. of $\mathrm{mCPBA}$ per sulfur atom. To avoid staying at the first oxidation state of the sulfur atom (sulfoxide), the mixture reaction was left $24 \mathrm{~h}$ (Scheme 4). After a filtration and a washing procedure (see ESI), a yield of $60 \%$ was achieved. The polymer turned from a clear yellow to a white powder after thioether oxidation.

Due to insolubility in DCM, the sulfonation of PHU 7 was conducted in DMF keeping the same reaction conditions. The polymer was then purified by dialysis in water, enabling its precipitation as well as the removal of DMF, mCPBA and its acidic form. Interestingly, both sulfones were obtained as

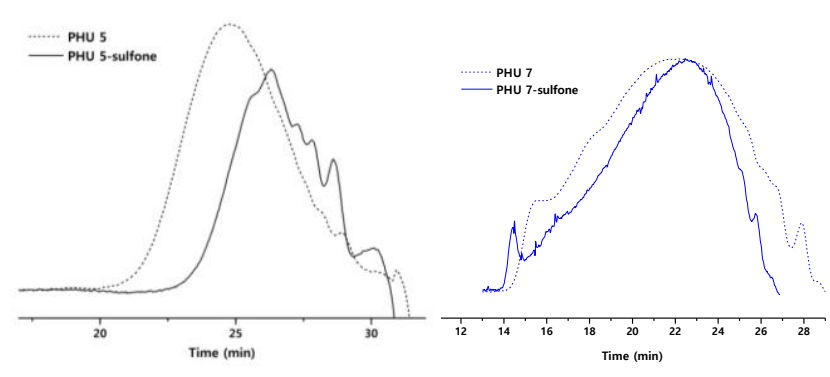

Figure 9- SEC traces of PHU 5 and PHU 7 before and after sulfonation (DMF, $\mathrm{LiBr}$, PS standards, RI detector).

white powders, highlighting the whitening power of $\mathrm{PHU}$ sulfonation.

FTIR confirmed the formation of sulfones with the presence of two bands of absorption at $1127 \mathrm{~cm}^{-1}$ and $1387 \mathrm{~cm}^{-1}$. Moreover, no new band in between 1030 and $1070 \mathrm{~cm}^{-1}$ characterizing sulfoxides was detected. Thanks to ${ }^{1} \mathrm{H},{ }^{13} \mathrm{C} N M R$ and $2 \mathrm{D} N \mathrm{NMR}$ (COSY, HSQC), the sulfonation was confirmed and fine chemical structures of PHU 5-sulfone and PHU 7-sulfone were elucidated and compared with unfunctionalized PHU (Figure 8 and ESI Figure 12).

All the signals initially present nearby the sulfur atom in PHU 5 (Spectra (1), Figure 8, 1' to $\mathbf{3}^{\prime}, \mathbf{1}^{\prime \prime}$ to $\mathbf{3}^{\prime \prime}$ and 4) were shifted downfield of the ${ }^{1} \mathrm{H}$ NMR spectra due to the electronic effects imparted by the sulfone. More specifically, the sulfonation was confirmed by the downfield signals of the protons adjacent to the sulfur atom (3', 3' and 4) to 3.5-2.75 ppm. The same proton shifts were observed on PHU 7-sulfone (ESI Figure 12). $M_{n}$ values of the post-functionalized PHUs were measured by SEC in DMF ( $\mathrm{LiBr}$, PS standards). Regarding the fatty acid-based PHU 5-sulfone, molar mass was evaluated at $2900 \mathrm{~g} . \mathrm{mol}^{-1}$ and was decreased by a factor 5 in comparison to PHU $\mathbf{5}$. The dispersity was also noticed to be lowered, from 1.86 to 1.43 , after thioether oxidation.

In a preliminary study, we tried to solubilize both sulfonated polymers in water, taking advantage of the high hydrogen bonding ability of the sulfone moiety. Nevertheless, they could not be solubilized in water because of the high amount of hydrophobic segments within the polymer backbone.

The SEC traces before and after post-functionalization are presented in Figure 9 and clearly display a significant loss of molar mass with the appearance of oligomers at higher retention times. Several parameters could be taken in consideration to explain such results. The depolymerization of PHU 5-sulfone could have occurred but this statement was not taken into account. Indeed, we carried out the reaction between mcpba and fatty acid-based PHU that do not contain thioether functions during 24h. No change in chemical structure (NMR spectrum) and molar masses (SEC traces) was detected before and after reaction, disqualifying the hypothesis of polymer chain cleavage. Secondly, the chemical modifications on a polymer can impact the shape of the polymer random coil, inducing a change of its hydrodynamic volume and of its subsequent apparent molar mass. But the most probable fact is a lack of solubility of PHU 5-sulfone in 

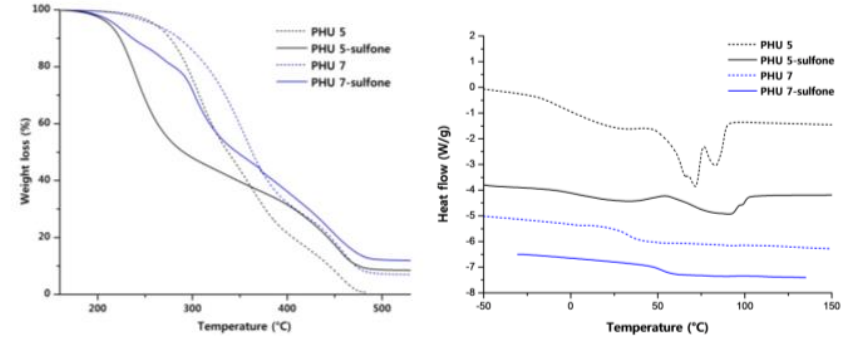

Figure 10 - DSC second heating cycles $\left(10^{\circ} \mathrm{C} / \mathrm{min}\right)$ of $\mathrm{PHU} 5$ and $\mathrm{PHU} 7$, before and after sulfonation, and corresponding TGA traces from 160 to 550 ${ }^{\circ} \mathrm{C}$ (after an isothermal procedure of $15 \mathrm{~min}$ at $160^{\circ} \mathrm{C}$ to remove the residual DMF).

DMF due to the presence of sulfone moieties along the backbone as it has already been observed in the literature for other polymers. ${ }^{39}$ Indeed, the longest functionalized polymer chains were not solubilized in DMF and therefore not analyzed. As a consequence, the SEC trace only shows the soluble fraction present in the filtered SEC solution. Contrarily, PHU 7 displayed similar dispersities and molar masses around 10000 g. mol ${ }^{-1}$ before and after post-functionalization due to a higher solubility in DMF.

Thermal properties of the post-functionalized PHUs were investigated by DSC and TGA and the results are reported in Table 3. With regard to PHU 5, the oxidized homologue was semi-crystalline, but showed higher glass transition and melting temperatures of respectively $4^{\circ} \mathrm{C}$ and $92^{\circ} \mathrm{C}$. Equivalently, the sulfonation of PHU 7 improved the material rigidity as indicated by the increase of the $\mathrm{T}_{\mathrm{g}}$ from 34 to $52^{\circ} \mathrm{C}$. However, the thermal decomposition at 5 wt.\% loss was decreased by approximately $40^{\circ} \mathrm{C}$ in both cases. These results were in contrast to what has been previously reported in the literature regarding fatty acid-based polysulfones. ${ }^{38,39}$

\section{Conclusion}

In conclusion, sulfur-substituted ( $\beta$ position) 5-membered cyclic carbonates were successfully synthesized via thiol-ene coupling of thioglycerol and fatty acid-based derivatives obtained from castor and sunflower oils. Trehalose was also used as a building block for the design of glycolipid-based cyclic carbonates. In model reaction with hexylamine, sulfursubstituted monomer displayed an enhanced reactivity towards aminolysis than aliphatic-substituted 5-membered cyclic carbonates, confirming the importance of thioether moieties within the structure. The designed monomers were then successfully polymerized leading to PHUs with molar masses up to 14900 g.mol-1. Depending on the monomer structure employed, $\mathrm{PHU}$ properties could be tuned with $\mathrm{T}_{\mathrm{g}}$ in the range -34 to $-56^{\circ} \mathrm{C}$ and $\mathrm{T}_{\mathrm{d} 5 \%}$ in between 240 and $286^{\circ} \mathrm{C}$.

To go further, two sulfur-based PHU were post-functionalized by sulfonation taking advantage of the thioethers within the polymer backbone. Such a modification was shown to increase the glass transition temperatures of the polymers as well as the melting temperature. However, polymer solubility was not radically impacted by the post-functionalization as it could be expected. To follow the same line, preparation of sulfonium salts from the thioether-containing PHUs would be an interesting way to tune properties.

Finally, this study has demonstrated the possibility of inserting a sulfur atom in $\beta$ position nearby the cyclic carbonate moiety via a simple thiol-ene reaction, taking advantage of the higher reactivity of such carbonates as well as the possibility of postfunctionalizing the resulting polymers via thioether functions. Further investigations on self-assembly, biodegradability and biocompatibility of the afore-described systems would be necessary to confirm their potential application in pharmaceutical and biomedical fields.

\section{Acknowledgements}

This work was performed, in partnership with the SAS PIVERT, within the frame of the French Institute for the Energy Transition (Institut pour la Transition Energétique - ITE) P.I.V.E.R.T. (www.institut-pivert.com) selected as an Investment for the Future ("Investissements d'Avenir"). This work was supported, as part of the Investments for the Future, by the French Government under the reference ANR-001-01. The authors thank also University of Bordeaux, Bordeaux INP, CNRS, Aquitaine Regional Council and ITERG for the financial support of a part of this research. Computer time for this study was provided by the computing facilities MCIA (Mésocentre de Calcul Intensif Aquitain) of the Universite de Bordeaux and of the Université de Pau et des Pays de l'Adour. Authors also thank Equipex Xyloforest ANR-10-EQPX-16 XYLOFOREST for flash chromatography.

\section{Notes and references}

(1) Maisonneuve, L.; Lamarzelle, O.; Rix, E.; Grau, E.; Cramail, H. Chem. Rev. 2015, 115 (22), 12407-12439.

(2) Nohra, B.; Candy, L.; Blanco, J.-F.; Guerin, C.; Raoul, Y.; Mouloungui, Z. Macromolecules 2013, 46 (10), 3771-3792. Cornille, A.; Auvergne, R.; Figovsky, O.; Boutevin, B.; Caillol, S. Eur. Polym. J. 2017, 87, 535-552.

(4) Engels, H. W.; Pirkl, H. G.; Albers, R.; Albach, R. W.; Krause, J.; Hoffmann, A.; Casselmann, H.; Dormish, J. Angew. Chemie - Int. Ed. 2013, 52 (36), 9422-9441.

(5) Maisonneuve, L.; Wirotius, A.-L.; Alfos, C.; Grau, E.; Cramail, H. Polym. Chem. 2014, 5, 6142-6147.

(6) Tomita, H.; Sanda, F.; Endo, T. J. Polym. Sci. Part A Polym. Chem. 2001, 39 (6), 860-867.

(7) Tomita, H.; Sanda, F.; Endo, T. J. Polym. Sci. Part A Polym. Chem. 2001, 39 (23), 4091-4100.

(8) Yuen, A.; Bossion, A.; Gómez-Bengoa, E.; Ruipérez, F.; Isik, M.; Hedrick, J. L.; Mecerreyes, D.; Yang, Y. Y.; Sardon, H. Polym. Chem. 2016, 7 (11), 2105-2111.

(9) Tomita, H.; Sanda, F.; Endo, T. J. Polym. Sci. Part A Polym. Chem. 2001, 39 (21), 3678-3685.

(10) Garipov, R. M.; Sysoev, V. A.; Mikheev, V. V; Zagidullin, A. I.; Deberdeev, R. Y.; Irzhak, V. I.; Berlin, A. Al. Dokl. Phys. Chem. 2003, 393 (1-3), 289-292.

(11) Lamarzelle, O.; Durand, P.-L.; Wirotius, A.-L.; Chollet, G.; 
Grau, E.; Cramail, H. Polym. Chem. 2016, 7, 1439-1451.

(12) He, Y.; Goel, V.; Keul, H.; Möller, M. Macromol. Chem. Phys. 2010, 211 (22), 2366-2381.

(13) Lambeth, R. H.; Henderson, T. J. Polymer (Guildf). 2013, 54 (21), 5568-5573.

(14) Blain, M.; Yau, H.; Jean-Gérard, L.; Auvergne, R.; Benazet, D.; Schreiner, P. R.; Caillol, S.; Andrioletti, B. ChemSusChem 2016, 9 (16), 2269-2272.

(15) Llevot, A.; Dannecker, P. K.; von Czapiewski, M.; Over, L. C. Söyler, Z.; Meier, M. A. R. Chem. - A Eur. J. 2016, 22 (33), 11510-11521.

(16) Maisonneuve, L.; More, A. S.; Foltran, S.; Alfos, C.; Robert, F.; Landais, Y.; Tassaing, T.; Grau, E.; Cramail, H. RSC Adv. 2014, 4 (49), 25795-25803.

(17) van Velthoven, J. L. J.; Gootjes, L.; van Es, D. S.; Noordover, B. A. J.; Meuldijk, J. Eur. Polym. J. 2015, 70, 125-135.

(18) Carré, C.; Zoccheddu, H.; Delalande, S.; Pichon, P.; Avérous, L. Eur. Polym. J. 2016.

(19) Besse, V.; Auvergne, R.; Carlotti, S.; Boutevin, G.; Otazaghine, B.; Caillol, S.; Pascault, J.-P.; Boutevin, B. React. Funct. Polym. 2013, 73 (3), 588-594.

(20) Proempers, G.; Keul, H.; Hoecker, H. Des. Monomers Polym. 2005, 8 (6), 547-569.

(21) Chen, Q.; Gao, K.; Peng, C.; Xie, H.; Zhao, Z. K.; Bao, M. Green Chem. 2015, 17, 4546-4551.

(22) Mnif, I.; Ghribi, D. J. Sci. Food Agric. 2016, No. October 2015, 4310-4320.

(23) Brandenburg, K.; Holst, O. eLS 2015, No. February, 1-9.

(24) Boyer, A.; Cloutet, E.; Tassaing, T.; Gadenne, B.; Alfos, C.; Cramail, H. Green Chem. 2010, 12 (12), 2205-2213.

(25) Besse, V.; Foyer, G.; Auvergne, R.; Caillol, S.; Boutevin, B. J. Polym. Sci. Part A Polym. Chem. 2013, 51 (15), 3284-3296.

(26) Benyahya, S.; Desroches, M.; Auvergne, R.; Carlotti, S.; Caillol, S.; Boutevin, B. Polym. Chem. 2011, 2 (11), 26612667.

(27) Dordick, J. S.; Rethwisch, D. G.; Patil, D. R. Biodegradable sugar-based polymers, WO199117255A1, 1991.

(28) Gross, R. A. 2014, 15 (11), 4214-4227.

(29) Türünç, O.; Meier, M. A. R. Macromol. Rapid Commun. 2010, 31 (20), 1822-1826.

(30) Bao, Y.; He, J.; Li, Y. Polym. Int. 2013, 62 (10), 1457-1464.

(31) Pyo, S.-H.; Persson, P.; Mollaahmad, M. A.; Sörensen, K.; Lundmark, S.; Hatti-Kaul, R. Pure Appl. Chem. 2012, 84, 411-860.

(32) Mouloungui, Z.; Yoo, J.-W.; Gachen, C.-A.; Gaset, A.; Vermeersch, G. Process for the preparation of glycerol carbonate from glycerol and ethylene or propylene carbonates, EP19960390003, 1996.

(33) Mignani, G.; Debray, J.; Da Silva, E.; Lemaire, M.; Raoul, Y. Method for producing polyglycerol poly(carbonate), WO2014009421, 2011.

(34) Türünç, O.; Meier, M. A. R. Eur. J. Lipid Sci. Technol. 2012, 115 (1), 41-54.

(35) Paul, N. K.; Twibanire, J. D. A. K.; Grindley, T. B. J. Org. Chem. 2013, 78 (2), 363-369.

(36) Twibanire, J. K.; Grindley, T. B. Org. Lett. 2011, 13 (12), 2988-2991.

(37) Zini, E.; Gazzano, M.; Scandola, M.; Wallner, S. R.; Gross, R.
A. 2008, 41 (20), 7463-7468.

(38) Van Den Berg, O.; Dispinar, T.; Hommez, B.; Du Prez, F. E. Eur. Polym. J. 2013, 49 (4), 804-812.

(39) Beyazkilic, Z.; Lligadas, G.; Ronda, J. C.; Galià, M.; Cádiz, V. Polymer (Guildf). 2015, 68 (0), 101-110. 


\title{
Design of original cyclic carbonates via thiol-ene coupling of thioglycerol with fatty acid and sugar derivatives towards poly(hydroxyurethane)s and polysulfones.
}

\author{
Océane Lamarzelle $^{\mathrm{a}, \mathrm{b}}$, Geoffrey Hibert ${ }^{\mathrm{a}, \mathrm{b}}$, Etienne Grau ${ }^{\mathrm{a}, \mathrm{b}}$ and Henri Cramail ${ }^{\mathrm{a}, \mathrm{b}^{*}}$
}

\section{Experimental and Supporting Information}

\section{Materials and Methods}

\section{Materials}

Sodium hydroxide $(\mathrm{NaOH}$, pellet), sodium hydride $(\mathrm{NaH}, 60 \%$ in oil), potassium carbonate $\left(\mathrm{K}_{2} \mathrm{CO}_{3}, 98 \%\right)$, tetrabutylammonium bromide (TBABr, 99\%), hexylamine (99\%), dimethyl carbonate (DMC, 99\%), 1,2,4-trichlorobenzene (TCB, 99\%), 1,5,7-triazabicyclodec-5-ene (TBD, 98\%), 2,2-bis(hydroxymethyl)propionic acid (DMPA, 98\%), ammonium chloride (99.5\%), sodium sulfate $\left(\mathrm{Na}_{2} \mathrm{SO}_{3}\right.$, magnesium sulfate $\left(\mathrm{MgSO}_{4}\right)$, sodium carbonate $\left(\mathrm{NaHCO}_{3}\right)$, 1thioglycerol (>99\%), 1-decene (94\%), meta-chloroperbenzoic acid (mCPBA, 77\%), O-

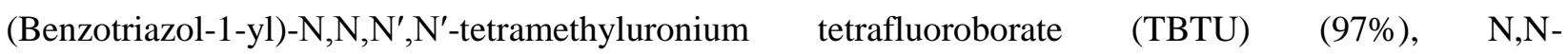
Diisopropylethylamine (DIPEA) (99\%), and Candida Antarctica Lipase B (CALB, polymer-bound) were obtained from Sigma-Aldrich. 1-bromo-10-undecene (96\%), was purchased from Alfa Aesar. Pyridine (>99\%), 10-undecen-1-ol (>98\%), methyl 10-undecenoate (>96.0\%), 1,10decanediamine (10DA, >98\%), 1,3-dioxane-2-one (trimethylene carbonate, TMC, >98\%) and 1,10-diaminodecane (10DA, >97\%) were supplied by TCI, Europe. Priamine ${ }^{\circledR} 1075$ was kindly supplied by CRODA. Oleyl alcohol (99.9\%), oleyl methanesulfonate (>99\%) and methyl oleate (99\%) were purchased from Nu-Check-Prep. Anhydrous trehalose (99\%) was purchased from Fisher

\section{Methods}

${ }^{1} \mathrm{H}$ and ${ }^{13} \mathrm{C}$-NMR spectra were recorded on Bruker Avance 400 spectrometer $(400.20 \mathrm{MHz}$ or 400.33 MHz and $100.63 \mathrm{MHz}$ for ${ }^{1} \mathrm{H}$ and ${ }^{13} \mathrm{C}$, respectively) by using $\mathrm{CDCl} 3$ as a solvent at room 
temperature, except otherwise mentioned. Two-dimensional analyses comprising ${ }^{1} \mathrm{H}-{ }^{1} \mathrm{H}$ COSY (COrrelation SpectroscopY) and ${ }^{1} \mathrm{H}_{-}{ }^{13} \mathrm{C}$ HSQC (Heteronuclear Single Quantum Spectroscopy) were also performed. Infrared spectra (FTIR-ATR) were obtained on a Bruker-Tensor 27 spectrometer, equipped with a diamond crystal, using the attenuated total reflection mode. The spectra were acquired using 16 scans at a resolution of 4 wavenumbers. The High-Performance Liquid Chromatography (HPLC) was performed at the ITERG using a Shimadzu instrument fitted with an Agilent PLgel 5 $\mu \mathrm{m}$ MIXED-D column $(300 \mathrm{~mm}, 7.5 \mathrm{~mm}$ diameter) and compounds were detected by a RID detector at $40^{\circ} \mathrm{C}$. The samples were diluted in THF at 10 $\mathrm{mg} . \mathrm{L}^{-1}$ and filtered before injection in the column. The analyses were performed with THF as eluent at $40^{\circ} \mathrm{C}$. Size exclusion chromatography (SEC) analyses of PHUs were performed in DMF $\left(25^{\circ} \mathrm{C}\right)$ on a PL-GPC 50 plus Integrated GPC from Polymer laboratories-Varian with a series of three columns from Polymer Laboratories (PLgel: PLgel 5 $\mu \mathrm{m}$ Guard (guard column $7.5 \mathrm{~mm}$ ID x $5.0 \mathrm{~cm} \mathrm{~L}$ ); PLgel $5 \mu \mathrm{m}$ MIXED-D (7.5 mm ID x $30.0 \mathrm{~cm} \mathrm{~L})$ and PLgel $5 \mu \mathrm{m}$ MIXED-D $(7.5 \mathrm{~mm}$ ID x $30.0 \mathrm{~cm} \mathrm{~L}))$. SEC were also performed in THF $\left(25^{\circ} \mathrm{C}\right)$ on a PL GPC50 and with four TSK columns: HXL-L (guard column), G4000HXL (particles of $5 \mathrm{~mm}$, pore size of 200A, and exclusion limit of $400000 \mathrm{~g} / \mathrm{mol}$ ), G3000HXL (particles of $5 \mathrm{~mm}$, pore size of 75A, and exclusion limit of $60000 \mathrm{~g} / \mathrm{mol}$ ), G2000HXL (particles of $5 \mathrm{~mm}$, pore size of $20 \mathrm{~A}$, and exclusion limit of $10000 \mathrm{~g} / \mathrm{mol}$ ) at an elution rate of $1 \mathrm{~mL} / \mathrm{min}$. In both cases, the elution times of the filtered samples were monitored using UV and RI detectors and SEC were calibrated using polystyrene standards. Differential scanning calorimetry (DSC) thermograms were measured using a DSC Q100 apparatus from TA instruments. For each sample, two cycles from -50 to 160 ${ }^{\circ} \mathrm{C}$ at $10{ }^{\circ} \mathrm{C}$.min-1 (additional isotherm of $15 \mathrm{~min}$ at $160^{\circ} \mathrm{C}$ at the end of the first cycle to remove the residual DMF) were performed and then the glass transition and melting temperatures were calculated from the second heating run. Thermogravimetric analyses (TGA) were performed on TGA-Q50 system from TA instruments at a heating rate of $10{ }^{\circ} \mathrm{C} \cdot \mathrm{min}^{-1}$ under nitrogen atmosphere from room temperature to $600^{\circ} \mathrm{C}$, with an isotherm at $160^{\circ} \mathrm{C}$ for $15 \mathrm{~min}$ to remove the residual DMF. DFT calculations were done using GAUSSIAN0932 with the B3PLYP hybrid functional and a high quality 6-311++G(d) basis set. 


\section{Experimental}

Und(ether)-diene synthesis: Into a round bottom flask, 2 eq. of sodium hydride $(0.55 \mathrm{~g}, 22.8$ mmol) were stirred with $70 \mathrm{~mL}$ of DMSO under inert atmosphere. 1 eq. of 10-undecen-1-ol (1.94 $\mathrm{g}, 11.4 \mathrm{mmol}$ ) was slowly added. The reaction mixture was then stirred at room temperature for $10 \mathrm{~min}$. To this, 1-bromo-10-undecene (2.66 g, $11.4 \mathrm{mmol})$ was added drop-wise. After 16h, DMSO was removed under reduced pressure and excess sodium hydride was deactivated by aqueous solution of ammonium chloride. DCM $(50 \mathrm{~mL})$ was added and the organic layer was washed with saturated $\mathrm{NaHCO}_{3} 3$ times and with water. The organic layer was dried over anhydrous magnesium sulphate, filtered and reconcentrated. Conversion: 100\%. The crude product was purified by flash column chromatography using a mixture of cyclohexane-ethyl acetate (100:0 to 80:20) as eluent and obtained as a white powder. Yield: $36 \%$. Purity by GC: 100\%. ${ }^{1} \mathrm{H}$ NMR $\left(\mathrm{CDCl}_{3}, 25^{\circ} \mathrm{C}, 400 \mathrm{MHz}\right), \delta(\mathrm{ppm}): 5.73(\mathrm{~m}, 2 \mathrm{H}), 4.96(\mathrm{~m}, 4 \mathrm{H}), 3.36(\mathrm{t}, 4 \mathrm{H})$, 1.94 (q, 4H), 1.49 (m, 4H), 1.20-1.27 (m, 24H).

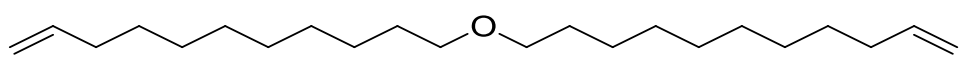

Oleyl(ether)-diene synthesis: Into a round bottom flask, 2 eq. of sodium hydride (0.89 g, 37.2 mmol) were stirred with $70 \mathrm{~mL}$ of DMSO under inert atmosphere. 1 eq. of oleyl alcohol $(5 \mathrm{~g}$, $18.6 \mathrm{mmol}$ ) was slowly added. The reaction mixture was then stirred at room temperature for 10 min. To this, oleyl methanesulfonate $(6.45 \mathrm{~g}, 18.6 \mathrm{mmol})$ was added drop-wise. After 16h, DMSO was removed under reduced pressure and excess sodium hydride was deactivated by aqueous solution of ammonium chloride. DCM $(50 \mathrm{~mL})$ was added and the organic layer was washed with saturated $\mathrm{NaHCO}_{3} 3$ times and with water. The organic layer was dried over anhydrous magnesium sulphate, filtered and reconcentrated. Conversion: 100\%. The crude product was purified by flash column chromatography using a mixture of cyclohexane-ethyl acetate (100:0 to 70:30) as eluent and obtained as viscous transparent oil. Yield: $37 \%$. Purity by GC: $100 \% .{ }^{1} \mathrm{H}$ NMR $\left(\mathrm{CDCl}_{3}, 25^{\circ} \mathrm{C}, 400 \mathrm{MHz}\right), \delta(\mathrm{ppm}): 5.33(\mathrm{~m}, 4 \mathrm{H}), 3.39(\mathrm{t}, 4 \mathrm{H}), 1.99(\mathrm{~m}$, $8 \mathrm{H}), 1.54(\mathrm{~m}, 4 \mathrm{H}), 1.30(\mathrm{~m}, 44 \mathrm{H}), 0.86(\mathrm{t}, 6 \mathrm{H})$.

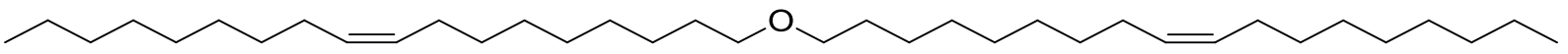


Und(ester)-diene synthesis: 1 eq. of methyl 10-undecenoate (17.47 g, $88 \mathrm{mmol}), 1$ eq. of 10 undecen-1-ol (15 g, $88 \mathrm{mmol})$ and 0.05 eq. of TBD were stirred under nitrogen flow $4 \mathrm{~h}$ at $120^{\circ} \mathrm{C}$, $2 \mathrm{~h}$ at $160^{\circ} \mathrm{C}$ then $1 \mathrm{~h}$ under vacuum at $160^{\circ} \mathrm{C}$. Conversion: $90 \%$. The product was purified using flash column chromatography (eluent: cyclohexane-ethyl acetate, 80:20) and obtained as a white powder. Yield: $83 \%$. Purity by GC: $100 \%$. ${ }^{1} \mathrm{H}$ NMR $\left(\mathrm{CDCl}_{3}, 25^{\circ} \mathrm{C}, 400 \mathrm{MHz}\right), \delta(\mathrm{ppm}): 5.81(\mathrm{~m}$, 2H), 4.97 (m, 4H), 4.07 (t, 2H), 2.28 (t, 2H), 2.03 (q, 4H), 1.64 (m, 4H), 1.38-1.29 (m, 24H).

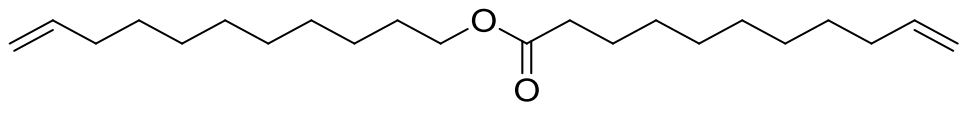

- General procedure for thiol-ene coupling: Dimerized bis-unsaturated fatty acids were reacted with thioglycerol in DCM using DMPA as photoinitiator. The reaction was carried out in a UV reactor $(365 \mathrm{~nm})$ for $1 \mathrm{~h}$, or $48 \mathrm{~h}$ in the case of the Oleyl(ether)-tetraol synthesis.

Dec-diol synthesis:1-decene (1 eq., 2 g, $14.3 \mathrm{mmol}$ ), thioglycerol (1 eq., 1.54 g, $14.3 \mathrm{mmol}$ ) were reacted in $2 \mathrm{~mL}$ of DCM for $1 \mathrm{~h}$ in a UV reactor, with $0.5 \mathrm{w} . \%$ of DMPA $(10 \mathrm{mg})$ as photoinitiator. Conversion: $100 \%$. The solvent was evaporated under reduced pressure and the product was obtained as a transparent oil after purification by flash chromatography (eluent: DCM:methanol from 100:0 to 95:5). Yield: 78\%. ${ }^{1} \mathrm{H}$ NMR (DMSO-d6, $25^{\circ} \mathrm{C}, 400 \mathrm{MHz}$ ), $\delta$ (ppm): $3.78(\mathrm{~m}, 1 \mathrm{H}), 3.73$ and $3.56(\mathrm{q}, 2 \mathrm{H}), 2.77$ and $2.61(\mathrm{dd}, 2 \mathrm{H}), 2.53(\mathrm{t}, 2 \mathrm{H}), 1.58(\mathrm{~m}, 2 \mathrm{H})$, $1.26(\mathrm{~m}, 14 \mathrm{H}), 0.85(\mathrm{t}, 3 \mathrm{H})$.

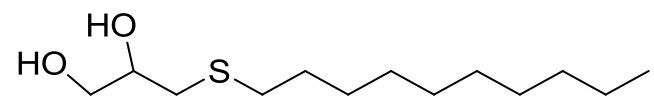

Und(ether)-tetraol synthesis: Und(ether)-diene (1 eq., 2 g, 6.2 mmol), thioglycerol (2 eq., 1.34 $\mathrm{g}, 12.4 \mathrm{mmol}$ ) were reacted in $2 \mathrm{~mL}$ of DCM for $1 \mathrm{~h}$ in a UV reactor, with $0.5 \mathrm{w} . \%$ of DMPA (10 $\mathrm{mg}$ ) as photoinitiator. Conversion: $100 \%$. The heterogeneous mixture obtained was filtered and the resulting white powder was abundantly washed with petroleum ether. Yield: $99 \%$. ${ }^{1} \mathrm{H}$ NMR (DMSO, $\left.25^{\circ} \mathrm{C}, 400 \mathrm{MHz}\right), \delta(\mathrm{ppm}): 4.58(\mathrm{~m}, 4 \mathrm{H}), 3.57$ (m, 2H), 3.35 (t, 4H), $3.33(\mathrm{t}, 4 \mathrm{H}), 2.62$ and $2.43(\mathrm{dd}, 4 \mathrm{H}), 2.53(\mathrm{t}, 4 \mathrm{H}), 1.52-1.27(\mathrm{~m}, 34 \mathrm{H})$.

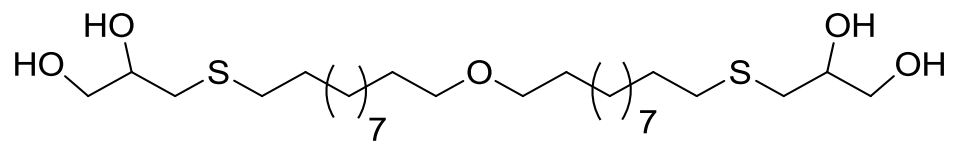


Oleyl(ether)-tetraol synthesis: Oleyl(ether)-diene (1 eq., $2.5 \mathrm{~g}, 4.82 \mathrm{mmol}$ ), thioglycerol ( 2 eq., $1.04 \mathrm{~g}, 9.6 \mathrm{mmol}$ ) were reacted in $2 \mathrm{~mL}$ of DCM for $48 \mathrm{~h}$ in a UV reactor, with $1.5 \mathrm{w} . \%$ of DMPA (38 mg) as photoinitiator. Conversion: $90 \%$. The solvent was evaporated and the crude product was purified by flash column chromatography (eluent: DCM:methanol from 100:0 to 90:10) to obtain a transparent viscous liquid. Yield: $30 \% .{ }^{1} \mathrm{H}$ NMR (DMSO-d6, $25^{\circ} \mathrm{C}, 400 \mathrm{MHz}$ ), $\delta(\mathrm{ppm}): 4.68(\mathrm{~d}, 2 \mathrm{H}), 4.51(\mathrm{t}, 2 \mathrm{H}), 3.51(\mathrm{~m}, 2 \mathrm{H}), 3.35(\mathrm{t}, 4 \mathrm{H}), 3.33(\mathrm{t}, 4 \mathrm{H}), 2.59(\mathrm{~m}, 2 \mathrm{H}), 2.54$ and $2.37(\mathrm{dd}, 4 \mathrm{H}), 1.45-1.25(\mathrm{~m}, 60 \mathrm{H}), 0.88(\mathrm{t}, 6 \mathrm{H})$.

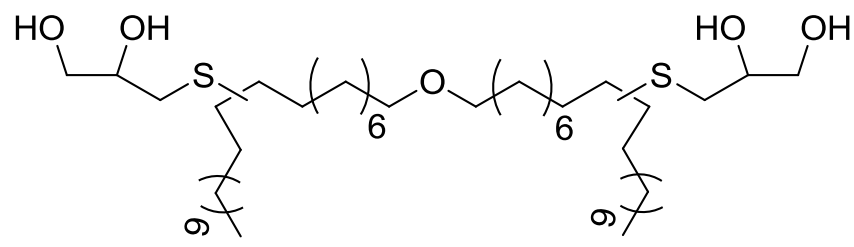

Und(ester)-tetraol synthesis: Und(ester)-diene ( 1 eq., $3 \mathrm{~g}, 8.9 \mathrm{mmol}$ ), thioglycerol (2 eq., $1.93 \mathrm{~g}$, $17.8 \mathrm{mmol}$ ) were reacted in $2 \mathrm{~mL}$ of DCM $1 \mathrm{~h}$ in a UV reactor, with $0.5 \mathrm{w} . \%$ of DMPA (15 mg) as photoinitiator. Conversion: $100 \%$. The heterogeneous mixture obtained was filtered and the resulting white powder was abundantly washed with petroleum ether. Yield: 99\%. ${ }^{1} \mathrm{H}$ NMR $\left(\mathrm{CDCl}_{3}, 25^{\circ} \mathrm{C}, 400 \mathrm{MHz}\right), \delta(\mathrm{ppm}): 4.07(\mathrm{t}, 2 \mathrm{H}), 3.78(\mathrm{~m}, 2 \mathrm{H}), 3.75$ and $3.35(\mathrm{q}, 4 \mathrm{H}), 2.73$ and $2.69(\mathrm{dd}, 4 \mathrm{H}), 2.62(\mathrm{t}, 4 \mathrm{H}), 2.30(\mathrm{~m}, 6 \mathrm{H}), 1.60-1.27(\mathrm{~m}, 34 \mathrm{H})$.

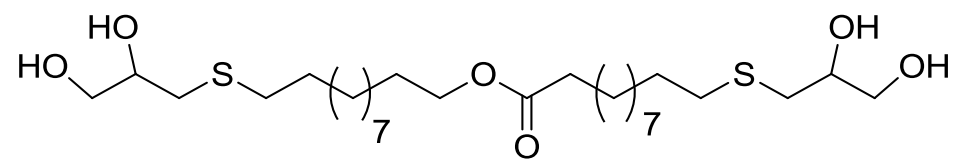

Methyl-Und-tetraol: Methyl 10-undecenoate (10 g, $50 \mathrm{mmol}$.) and 1-thioglycerol (2 eq., $10 \mathrm{~g}$, $100 \mathrm{mmol}$ ) were stirred during $2 \mathrm{~h}$ under irradiation using UV light $(\lambda=365 \mathrm{~nm})$. Then the reaction was quenched by turning off the UV light. Purification over silica gel flash chromatography was performed using DCM/MeOH 98/2 eluent. Yield: $80 \% .{ }^{1} \mathrm{H} \mathrm{NMR}\left(\mathrm{CDCl}_{3}\right.$, $400 \mathrm{MHz}), \delta$ (ppm): 3.74 (m, 2H), 3.64 (s, 3H), 3.53 (m, 1H), 2.65 (m, 2H), 2.51 (m, 2H), $2.28(\mathrm{t}$, $2 \mathrm{H}), 1.59-1.25(\mathrm{~m}, 16 \mathrm{H})$.

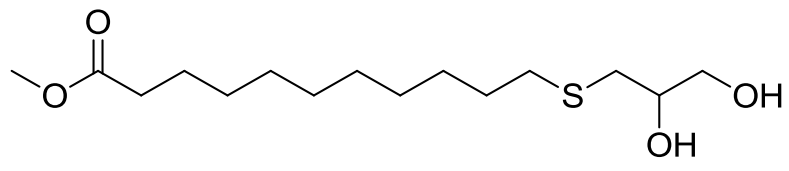


Methyl-Oleyl-tetraol: Methyl oleate (10 g, 33 mmol.) and 1-thioglycerol (10 eq., 36 g, 337 mmol) were stirred under irradiation using UV light $(\lambda=365 \mathrm{~nm})$ until total conversion of the internal double bond. Then the reaction was quenched by turning off the UV light. Purification over silica gel flash chromatography was performed using DCM/MeOH 98/2 eluent. Yield: $76 \%$. ${ }^{1} \mathrm{H} \mathrm{NMR}\left(\mathrm{CDCl}_{3}, 400 \mathrm{MHz}\right), \delta(\mathrm{ppm}): 3.72(\mathrm{~m}, 2 \mathrm{H}), 3.63(\mathrm{~s}, 3 \mathrm{H}), 3.53(\mathrm{~m}, 1 \mathrm{H}), 2.63(\mathrm{~m}, 3 \mathrm{H})$, $2.27(\mathrm{t}, 2 \mathrm{H}), 1.58-1.24(\mathrm{~m}, 26 \mathrm{H}), 0.85(\mathrm{t}, 3 \mathrm{H})$.

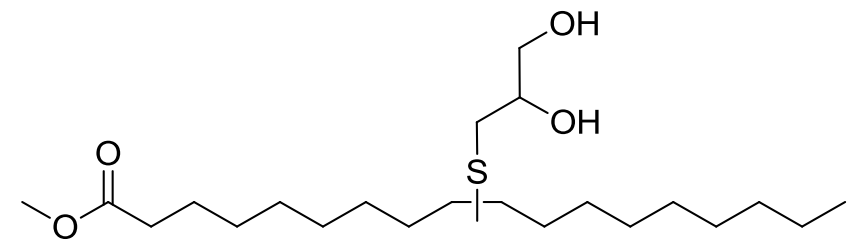

- General procedure for carbonation: Fatty acids tetraols were dried under vacuum and were subsequently reacted under nitrogen atmosphere with an excess of anhydrous dimethylcarbonate (DMC, 15 eq.), using 3 mol.\% of $\mathrm{K}_{2} \mathrm{CO}_{3}$ per diol as transesterification catalyst. The reaction was carried out for $4 \mathrm{~h}$ at $70^{\circ} \mathrm{C}$ under reflux.

Dec-CC-S synthesis: Dec-diol (1 eq., 1 g, 7 mmol), DMC (15 eq., $8.5 \mathrm{~mL}, 105 \mathrm{mmol}), \mathrm{K}_{2} \mathrm{CO}_{3}$ (0.03 eq., $29 \mathrm{mg}, 0.21 \mathrm{mmol}$ ). Conversion: 100\%. DCM was added to the crude mixture and washed with brine three times. The organic phase was dried with magnesium sulfate and reconcentrated using a rotary evaporator. The product was obtained as a transparent viscous liquid after purification by flash column chromatography (eluent: DCM:methanol from 100:0 to 95:5). Yield: 30\%. Purity: 90.1\% (HPLC). ${ }^{1} \mathrm{H}$ NMR $\left(\mathrm{CDCl}_{3}, 25^{\circ} \mathrm{C}, 400 \mathrm{MHz}\right), \delta$ (ppm): 4.84 (m, $1 \mathrm{H}), 4.55$ and $4.31(\mathrm{t}, 2 \mathrm{H}), 2.94$ and $2.77(\mathrm{dd}, 2 \mathrm{H}), 2.59(\mathrm{t}, 2 \mathrm{H}), 1.58(\mathrm{~m}, 2 \mathrm{H}), 1.37-1.26(\mathrm{~m}$, $14 \mathrm{H}), 0.86(\mathrm{t}, 3 \mathrm{H}) .{ }^{13} \mathrm{C} \mathrm{NMR}\left(\mathrm{CDCl}_{3}, 25^{\circ} \mathrm{C}, 100 \mathrm{MHz}\right), \delta(\mathrm{ppm}): 154.5(\mathrm{O}-\mathrm{C}=\mathrm{O}-\mathrm{O}), 75.6\left(\mathrm{CH}_{2}-\right.$ $\left.\underline{\mathrm{CH}}-\mathrm{CH}_{2}\right), 68.7\left(\mathrm{O}-\underline{\mathrm{CH}}_{2}-\mathrm{CH}\right), 34.7\left(\mathrm{CH}_{2}-\mathrm{CH}-\underline{\mathrm{CH}}{ }_{2}-\mathrm{S}\right), 33.2\left(\mathrm{~S}_{-} \underline{\mathrm{CH}}_{2}-\mathrm{CH}_{2}\right), 32-23\left(\mathrm{CH}_{2}\right), 14.4$ $\left(\mathrm{CH}_{3}\right)$.

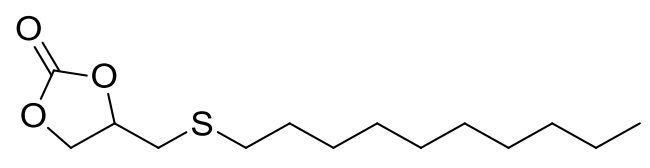

Und(ether)-bCC-S synthesis: Und(ether)-tetraol (1 eq., $1 \mathrm{~g}, 1.86 \mathrm{mmol}$ ), DMC (15 eq., $2.34 \mathrm{~mL}$, $28 \mathrm{mmol}$ ), $\mathrm{K}_{2} \mathrm{CO}_{3}$ (0.06 eq., $15 \mathrm{mg}, 0.11 \mathrm{mmol}$ ). Conversion: 100\%. DCM was added to the crude mixture and washed with brine three times. The organic phase was dried with magnesium 
sulfate and reconcentrated using a rotary evaporator. The product was obtained as a white powder. Yield: $88 \%$. Purity: $95.4 \%$ (HPLC). ${ }^{1} \mathrm{H}$ NMR (DMSO-d6, $25^{\circ} \mathrm{C}, 400 \mathrm{MHz}$ ), $\delta(\mathrm{ppm}$ ): $4.82(\mathrm{~m}, 2 \mathrm{H}), 4.57$ and $4.27(\mathrm{t}, 4 \mathrm{H}), 3.37(\mathrm{t}, 4 \mathrm{H}), 2.91$ and $2.75(\mathrm{dd}, 4 \mathrm{H}), 2.57(\mathrm{t}, 4 \mathrm{H}), 1.56-1.27$ (m, 34H). ${ }^{13} \mathrm{C}$ NMR (DMSO, $\left.25^{\circ} \mathrm{C}, 100 \mathrm{MHz}\right), \delta(\mathrm{ppm}): 154.6(\mathrm{O}-\mathrm{C}=\mathrm{O}-\mathrm{O}), 75.6\left(\mathrm{CH}_{2}-\underline{\mathrm{C}} \mathrm{H}-\right.$ $\left.\mathrm{CH}_{2}\right), 71.2\left(\underline{\mathrm{CH}}_{2}-\mathrm{O}-\mathrm{CH}_{2}\right), 68.8\left(\mathrm{O}-\underline{\mathrm{C}} \mathrm{H}_{2}-\mathrm{CH}\right), 34.9\left(\mathrm{CH}-\underline{\mathrm{CH}_{2}}-\mathrm{S}\right), 33.2\left(\mathrm{~S}^{-} \mathrm{CH}_{2}-\mathrm{CH}_{2}\right), 30-26.1$ $\left(\mathrm{CH}_{2}\right) \cdot \mathrm{T}_{\mathrm{m}}=93^{\circ} \mathrm{C}$.

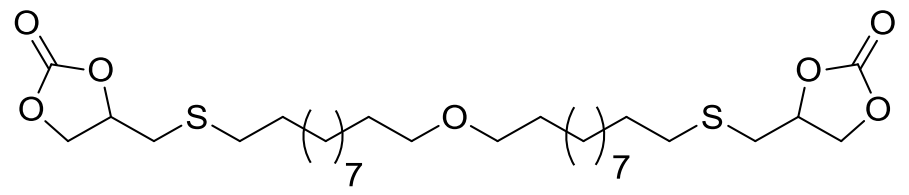

Oleyl(ether)-bCC-S synthesis: Oleyl(ether)-tetraol (1 eq., 0.75 g, 1 mmol), DMC (15 eq., 1.26 $\mathrm{mL}, 15 \mathrm{mmol}$ ), $\mathrm{K}_{2} \mathrm{CO}_{3}$ (0.06 eq., $8.3 \mathrm{mg}, 0.11 \mathrm{mmol}$ ). Conversion: $97 \%$. DCM was added to the crude mixture and washed with brine three times. The organic phase was dried with magnesium sulfate and reconcentrated using a rotary evaporator. The product was obtained as a viscous transparent liquid. Yield: $71 \%$. Purity: $98.5 \%$ (HPLC). ${ }^{1} \mathrm{H}$ NMR $\left(\mathrm{CDCl}_{3}, 25^{\circ} \mathrm{C}, 400 \mathrm{MHz}\right), \delta$ (ppm): $4.78(\mathrm{~m}, 2 \mathrm{H}), 4.53$ and $4.28(\mathrm{t}, 4 \mathrm{H}), 3.38(\mathrm{t}, 4 \mathrm{H}), 2.90$ and $2.72(\mathrm{dd}, 4 \mathrm{H}), 2.12(\mathrm{~m}, 2 \mathrm{H})$, 1.60-1.26 (m, 60H), $0.87(\mathrm{t}, 6 \mathrm{H}) .{ }^{13} \mathrm{C} \mathrm{NMR}\left(\mathrm{CDCl}_{3}, 25^{\circ} \mathrm{C}, 100 \mathrm{MHz}\right), \delta(\mathrm{ppm}): 154.9(\mathrm{O}-\mathrm{C}=\mathrm{O}-$ O), $75.7\left(\mathrm{CH}_{2}-\underline{\mathrm{CH}}-\mathrm{CH}_{2}-\mathrm{S}\right), 71.4\left(\underline{\mathrm{CH}}_{2}-\mathrm{O}-\mathrm{CH}_{2}\right), 68.5\left(\mathrm{O}-\underline{\mathrm{CH}}_{2}-\mathrm{CH}\right), 47.3\left(\mathrm{~S}-\underline{\mathrm{CH}}-\mathrm{CH}_{2}\right), 32.9(\underline{\mathrm{C} H}-$ $\left.\mathrm{CH}_{2}-\mathrm{S}-\mathrm{CH}\right), 35-22.8\left(\mathrm{CH}_{2}\right), 14.1\left(\mathrm{CH}_{3}\right) \cdot \mathrm{T}_{\mathrm{m}}=\mathrm{nd}, \mathrm{T}_{\mathrm{g}}=-59^{\circ} \mathrm{C}$.

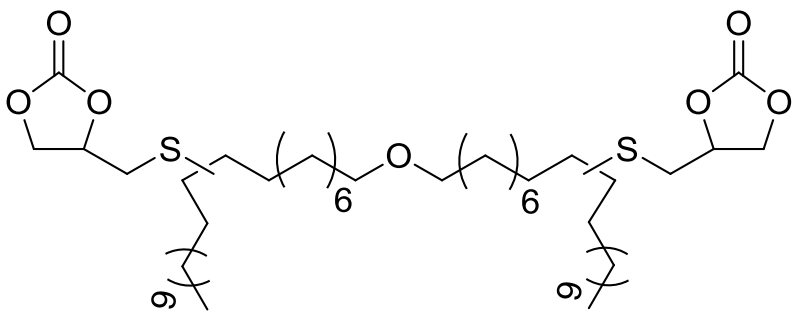

Und(ester)-bCC-S synthesis: Und(ester)-tetraol (1 eq., 0.75 g, 1.36 mmol), DMC (15 eq., 1.71 $\mathrm{mL}, 20.4 \mathrm{mmol}$ ), $\mathrm{K}_{2} \mathrm{CO}_{3}$ (0.06 eq., $11 \mathrm{mg}, 0.08 \mathrm{mmol}$ ). Conversion: $99 \%$. DCM was added to the crude mixture and washed with brine three times. The organic phase was dried with magnesium sulfate and reconcentrated using a rotary evaporator. The product was obtained as a white powder. Yield: 90\%. Purity: 88.9\% (HPLC). ${ }^{1} \mathrm{H} \mathrm{NMR}\left(\mathrm{CDCl}_{3}, 25^{\circ} \mathrm{C}, 400 \mathrm{MHz}\right), \delta$ (ppm): 4.83 $(\mathrm{m}, 2 \mathrm{H}), 4.75$ and $4.29(\mathrm{t}, 4 \mathrm{H}), 4.04(\mathrm{t}, 2 \mathrm{H}), 2.94$ and $2.79(\mathrm{dd}, 4 \mathrm{H}), 2.60(\mathrm{t}, 4 \mathrm{H}), 2.29(\mathrm{t}, 2 \mathrm{H})$, 
1.58-1.28 (m, 34H). ${ }^{13} \mathrm{C}$ NMR ( $\left.\mathrm{CDCl}_{3}, 25^{\circ} \mathrm{C}, 100 \mathrm{MHz}\right), \delta(\mathrm{ppm}): 174.2\left(\mathrm{CH}_{2}-\mathrm{C}=\mathrm{O}-\mathrm{O}-\right), 154.8$ $(\mathrm{O}-\mathrm{C}=\mathrm{O}-\mathrm{O}), 75.7\left(\mathrm{CH}_{2}-\underline{\mathrm{C}} \mathrm{H}-\mathrm{CH}_{2}\right), 68.6\left(\mathrm{O}-\underline{\mathrm{C}} \mathrm{H}_{2}-\mathrm{CH}\right), 64.5\left(\mathrm{O}=\mathrm{C}-\mathrm{O}-\underline{\mathrm{CH}}_{2}\right), 34.9\left(\mathrm{CH}-\underline{\mathrm{CH}_{2}}-\mathrm{S}\right), 34.7$ $\left(\mathrm{CH}_{2}-\mathrm{C}=\mathrm{O}-\mathrm{O}-\mathrm{CH}_{2}\right), 33.3\left(\mathrm{~S}-\underline{\mathrm{CH}}_{2}-\mathrm{CH}_{2}\right), 29.9-28.9\left(\mathrm{CH}_{2}\right) . \mathrm{T}_{\mathrm{m}}=89^{\circ} \mathrm{C}$.

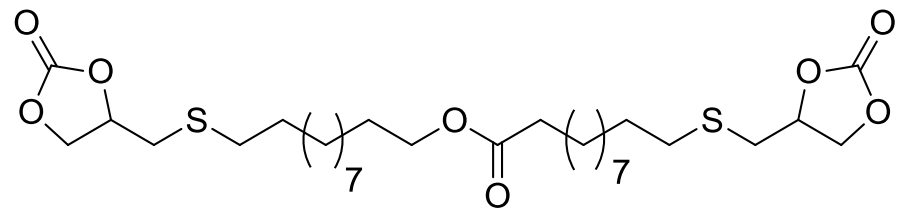

Und(ester)-CC-S: In a flame-dried round bottom flask equipped with a reflux condenser, (3 mol.\%, $68 \mathrm{mg}, 0.5 \mathrm{mmol})$ potassium carbonate $\left(\mathrm{K}_{2} \mathrm{CO}_{3}\right)$ was added to a solution of Methyl-Undtetraol (5 g, $16.3 \mathrm{mmol})$ dissolved in dimethyl carbonate (DMC) (25 eq., $34 \mathrm{~mL}, 0.4 \mathrm{~mol})$. The reaction mixture was stirred during $6 \mathrm{~h}$ under reflux. At the end of the reaction, the DMC was evaporated with a rotary evaporator. Purification over silica gel flash chromatography was performed using DCM/MeOH 98/2 eluent. ${ }^{1} \mathrm{H}$ NMR $\left(\mathrm{CDCl}_{3}, 400 \mathrm{MHz}\right), \delta(\mathrm{ppm}): 4.83$ (m, 1H), $4.57(\mathrm{~m}, 1 \mathrm{H}), 4.28(\mathrm{~m}, 1 \mathrm{H}), 3.66(\mathrm{~s}, 3 \mathrm{H}), 2.91(\mathrm{~m}, 2 \mathrm{H}), 2.59(\mathrm{t}, 2 \mathrm{H}), 2.30(\mathrm{t}, 2 \mathrm{H}), 1.56-1.27(\mathrm{~m}$, $16 \mathrm{H})$.

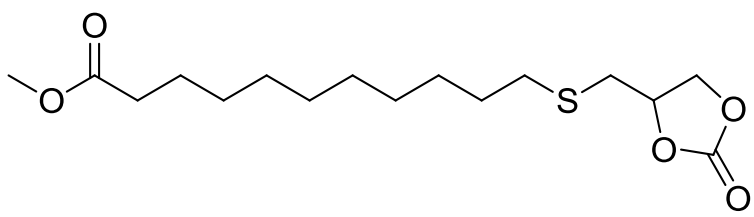

Oleyl(ester)-CC-S: In a flame-dried round bottom flask equipped with a reflux condenser, potassium carbonate $\left(\mathrm{K}_{2} \mathrm{CO}_{3} 3 \mathrm{~mol} . \%, 48 \mathrm{mg}, 0.3 \mathrm{mmol}\right.$.) was added to a solution of MethylOleyl-tetraol (5 g, 11.6 mmol.) dissolved in dimethyl carbonate (DMC 25 eq., $24 \mathrm{~mL}, 0.3$ mol.). The reaction mixture was stirred during $6 \mathrm{~h}$ under reflux. At the end of the reaction, the DMC was evaporated with a rotary evaporator. Purification over silica gel flash chromatography was performed using DCM/MeOH 98/2 eluent. ${ }^{1} \mathrm{H}$ NMR (DMSO-d6, $400 \mathrm{MHz}$ ), $\delta$ (ppm): 4.92 (m, $1 \mathrm{H}), 4.57(\mathrm{~m}, 1 \mathrm{H}), 4.19(\mathrm{~m}, 1 \mathrm{H}), 3.57(\mathrm{~s}, 3 \mathrm{H}), 2.88(\mathrm{~m}, 2 \mathrm{H}), 2.69(\mathrm{t}, 2 \mathrm{H}), 2.28(\mathrm{t}, 2 \mathrm{H}), 1.51-1.25$ (m, 16H), $0.86(\mathrm{t}, 3 \mathrm{H})$.

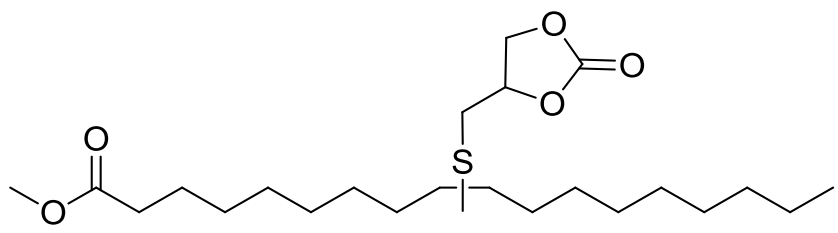


- General procedure for ester hydrolysis: Carbonated fatty acids methyl esters were hydrolyzed with lipase B from Candida Antarctica in water/acetone mixture (1:1) for $48 \mathrm{~h}$ at $60^{\circ} \mathrm{C}$.

Und(acid)-CC-S: In a round bottom flask, Und(ester)-CC-S (5 g, $15 \mathrm{mmol}$.) was dissolved in a solution water/acetone (2:5) (2 mL/10 mL). Then, lipase B from Candida Antartica (1g, $20 \mathrm{wt} . \%)$ was added to the reaction medium. The reaction mixture was stirred during $48 \mathrm{~h}$ at $60^{\circ} \mathrm{C}$. At the end of the reaction, the solvent was evaporated with a rotary evaporator. Purification over silica gel flash chromatography was performed using DCM/MeOH 98/2. ${ }^{1} \mathrm{H} \mathrm{NMR}\left(\mathrm{CDCl}_{3}, 400 \mathrm{MHz}\right)$, $\delta(\mathrm{ppm}): 4.83(\mathrm{~m}, 1 \mathrm{H}), 4.57(\mathrm{~m}, 1 \mathrm{H}), 4.28(\mathrm{~m}, 1 \mathrm{H}), 2.91(\mathrm{~m}, 2 \mathrm{H}), 2.59(\mathrm{t}, 2 \mathrm{H}), 2.30(\mathrm{t}, 2 \mathrm{H}), 1.56-$ $1.27(\mathrm{~m}, 16 \mathrm{H})$.

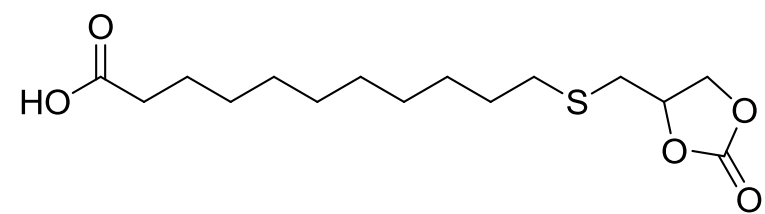

Oleyl(acid)-CC-S: In a round bottom flask, Oleyl(ester)-CC-S (5 g, $11 \mathrm{mmol}$.) was dissolved in a solution water/acetone (2:5) (4 mL/10 mL). Then, lipase B from Candida Antartica (1g, $20 \mathrm{wt} . \%)$ was added to the reaction medium. The reaction mixture was stirred during $48 \mathrm{~h}$ at $60^{\circ} \mathrm{C}$. At the end of the reaction, the solvent was evaporated with a rotary evaporator. Purification over silica gel flash chromatography was performed using DCM/MeOH 98/2. ${ }^{1} \mathrm{H}$ NMR (DMSO-d6, 400 MHz), $\delta(\mathrm{ppm}): 4.92(\mathrm{~m}, 1 \mathrm{H}), 4.57(\mathrm{~m}, 1 \mathrm{H}), 4.19(\mathrm{~m}, 1 \mathrm{H}), 2.88(\mathrm{~m}, 2 \mathrm{H}), 2.69(\mathrm{t}, 2 \mathrm{H}), 2.28(\mathrm{t}$, $2 \mathrm{H}), 1.51-1.25(\mathrm{~m}, 16 \mathrm{H}), 0.86(\mathrm{t}, 3 \mathrm{H})$.

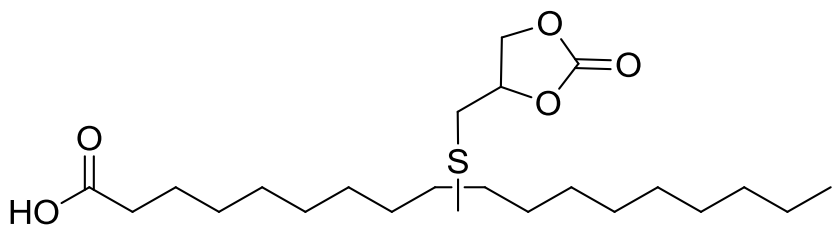

- General procedure for trehalose diester synthesis: In an oven-dried round bottomed flask equipped with a magnetic stir bar, fatty acid (2.1 equiv), TBTU (2.1 equiv) and DIPEA (4 equiv) were dissolved in dry pyridine. The resulting mixture was stirred at room temperature for $30 \mathrm{~min}$ under a nitrogen atmosphere. A solution of trehalose (1 eq) in dry pyridine was then slowly injected into the reaction mixture and stirred at room temperature for $72 \mathrm{~h}$. 
Trehal-Und-bCC-S: In a flame-dried round bottom flask equipped, $\boldsymbol{U n d}(\boldsymbol{a c i d})$-CC-S (2.1 eq., 3.9 g, 12 mmol.), TBTU (2.1 eq., 3.9 g, 12 mmol.) and DIPEA (2 eq., $1.9 \mathrm{~mL}, 11 \mathrm{mmol}$ ) were dissolved in dry pyridine $(20 \mathrm{~mL})$. The resulting mixture was stirred at room temperature for 30 min under a nitrogen atmosphere. Then the reaction mixture was slowly injected into a solution of trehalose $(1 \mathrm{eq}, 5.8 \mathrm{mmol})$ in dry pyridine $(20 \mathrm{~mL})$ and stirring was continued at room temperature for $72 \mathrm{~h}$. Pyridine was removed under vacuum and the resulting residue centrifuged in water to remove the by-products of the reaction. The precipitate was dried and purified by flash chromatography using an elution gradient of 5-25\% methanol in EtOAc-DCM (1:1) to give diester of trehalose as a gummy solid. Purity: $81.1 \%$ (HPLC). ${ }^{1} \mathrm{H}$ NMR (DMSO-d $\left.6,400 \mathrm{MHz}\right), \delta$ (ppm): $5.06(\mathrm{~d}, 2 \mathrm{H}), 4.96(\mathrm{~m}, 1 \mathrm{H}), 4.90(\mathrm{~d}, 2 \mathrm{H}), 4.81(\mathrm{~d}, 2 \mathrm{H}), 4.77(\mathrm{~d}, 2 \mathrm{H}), 4.58(\mathrm{~m}, 2 \mathrm{H}), 4.21(\mathrm{~d}$, 2H), $4.20(\mathrm{~m}, 2 \mathrm{H}), 4.04(\mathrm{~m}, 2 \mathrm{H}), 3.88(\mathrm{~m}, 2 \mathrm{H}), 3.54(\mathrm{~m}, 2 \mathrm{H}), 3.25(\mathrm{~m}, 2 \mathrm{H}), 3.11(\mathrm{~m}, 2 \mathrm{H}), 2.90$ $(\mathrm{m}, 2 \mathrm{H}), 2.54(\mathrm{t}, 2 \mathrm{H}), 2.27(\mathrm{t}, 2 \mathrm{H}), 1.51-1.24(\mathrm{~m}, 16 \mathrm{H}) .{ }^{13} \mathrm{C} \mathrm{NMR}\left(\mathrm{DMSO}-\mathrm{d}_{6}, 100 \mathrm{MHz}\right) \delta(\mathrm{ppm})$ :

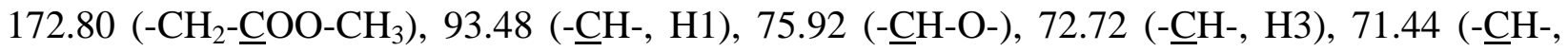

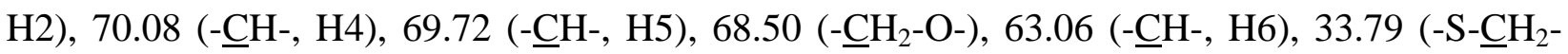
$\mathrm{CH}-), 33.55\left(-\underline{\mathrm{CH}}_{2}-\mathrm{COO}-\mathrm{CH}_{3}\right), 31.85\left(-\mathrm{CH}_{2}-\underline{\mathrm{CH}}_{2}-\mathrm{S}-\mathrm{CH}_{2}-\right), 29.17$ - 24.48 (aliphatic - $\underline{\mathrm{H}}_{2}-$ ). $\mathrm{T}_{\mathrm{m}}=120^{\circ} \mathrm{C}$.

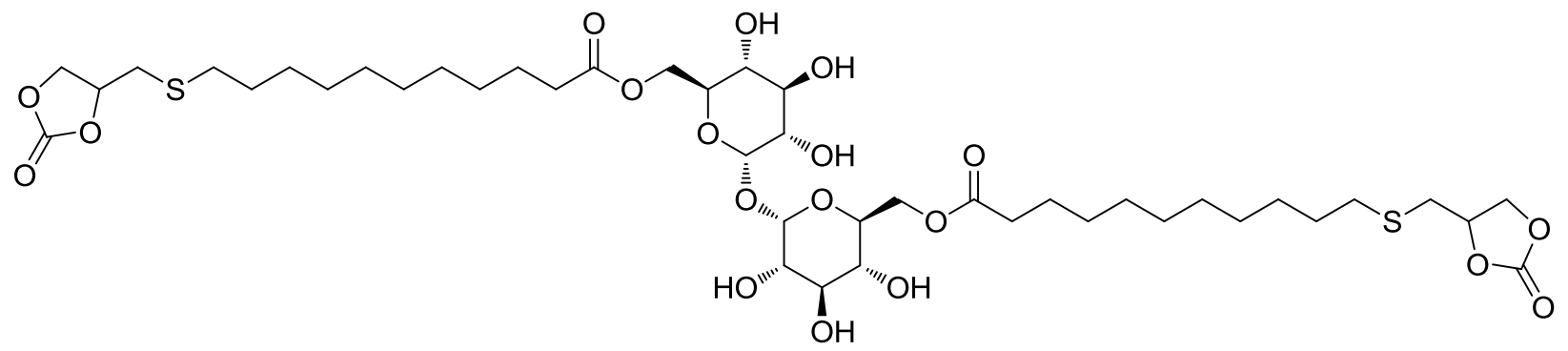

Trehal-Oleyl-CC-S: In a flame-dried round bottom flask equipped, Oleyl(acid)-CC-S (2.1 eq., $2.5 \mathrm{~g}, 6.1 \mathrm{mmol}$.), TBTU (2.1 eq., $1.9 \mathrm{~g}, 6.1 \mathrm{mmol}$ ) and DIPEA (2 eq., $0.9 \mathrm{~mL}, 5.8 \mathrm{mmol}$ ) were dissolved in dry pyridine $(15 \mathrm{~mL})$. The resulting mixture was stirred at room temperature for 30 min under a nitrogen atmosphere. Then the reaction mixture was slowly injected into a solution of trehalose (1 eq., $5.8 \mathrm{mmol})$ in dry pyridine $(15 \mathrm{~mL})$ and stirring was continued at room temperature for $72 \mathrm{~h}$. Pyridine was removed under vacuum and the resulting residue centrifuged in water to remove the by-products of the reaction. The precipitate was dried and purified by flash chromatography using an elution gradient of 5-25\% methanol in EtOAc-DCM (1:1) to give diester of trehalose as a gummy solid. Purity: $98.5 \%$ (HPLC). ${ }^{1} \mathrm{H}$ NMR (DMSO-d $\left.6,400 \mathrm{MHz}\right), \delta$ 
(ppm): $5.04(\mathrm{~d}, 2 \mathrm{H}), 4.92(\mathrm{~m}, 1 \mathrm{H}), 4.89(\mathrm{~d}, 2 \mathrm{H}), 4.82(\mathrm{~d}, 2 \mathrm{H}), 4.76(\mathrm{~d}, 2 \mathrm{H}), 4.57(\mathrm{~m}, 2 \mathrm{H}), 4.24(\mathrm{~d}$, 2H), $4.19(\mathrm{~m}, 2 \mathrm{H}), 4.03(\mathrm{~m}, 2 \mathrm{H}), 3.88(\mathrm{~m}, 2 \mathrm{H}), 3.54(\mathrm{~m}, 2 \mathrm{H}), 3.25(\mathrm{~m}, 2 \mathrm{H}), 3.12(\mathrm{~m}, 2 \mathrm{H}), 2.88$ $(\mathrm{m}, 2 \mathrm{H}), 2.69(\mathrm{t}, 2 \mathrm{H}), 2.28(\mathrm{t}, 2 \mathrm{H}), 1.51-1.25(\mathrm{~m}, 16 \mathrm{H}), 0.86(\mathrm{t}, 3 \mathrm{H}) .{ }^{13} \mathrm{C}$ NMR (DMSO-d 6,100

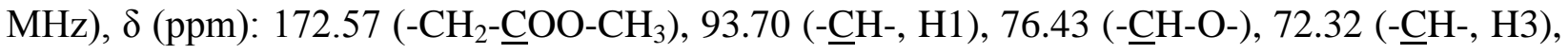

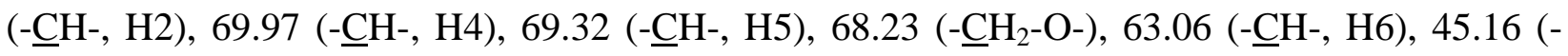
$\left.\mathrm{CH}_{2}-\underline{\mathrm{CH}}_{2}-\mathrm{S}-\mathrm{CH}_{2}-\right), 33.33$ (- $\underline{\mathrm{CH}}_{2}-\mathrm{COO}-\mathrm{CH}_{3}$ ), 32.46 (-S- $\underline{\mathrm{CH}}_{2}-\mathrm{CH}-$ ), 30.73 - 22.34 (aliphatic - $\underline{\mathrm{H}}_{2}-$ ), $13.94\left(-\mathrm{CH}_{3}\right) \cdot \mathrm{T}_{\mathrm{m}}=109^{\circ} \mathrm{C}$.

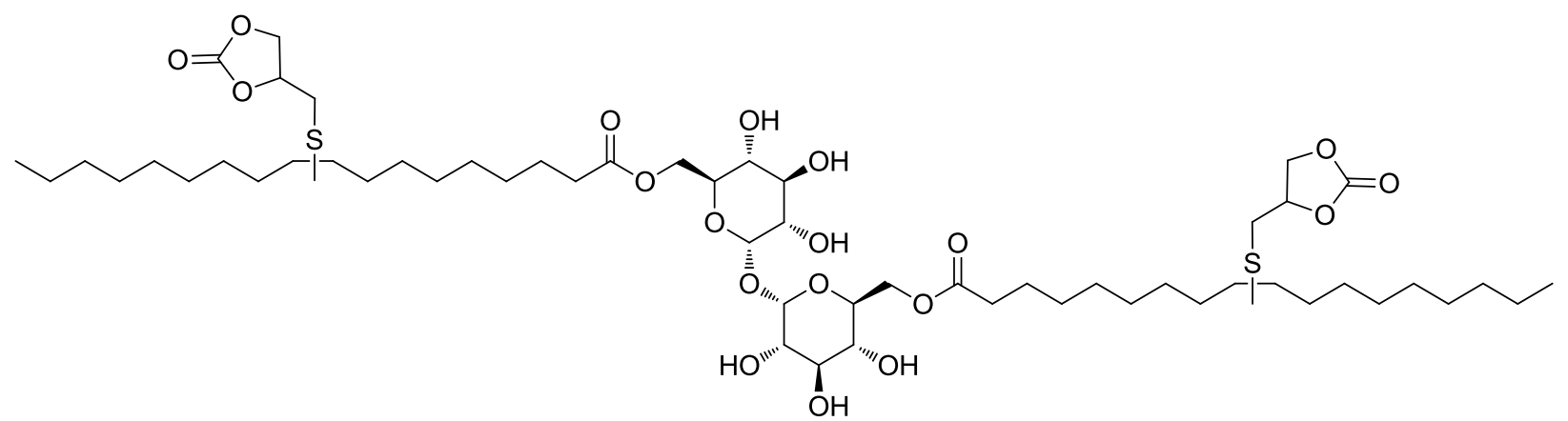

- General procedure for kinetic experiments: The kinetic experiments were performed in NMR tube at $1 \mathrm{~mol} . \mathrm{L}^{-1}$ in DMSO-d6, at $50^{\circ} \mathrm{C}$ and with a ratio $1: 1$ between cyclic carbonate and hexylamine. All reagents were dried on molecular sieves or distilled before the reaction. Hexylamine was dried under $\mathrm{CaH}_{2}$ and distilled of after drying. The cyclic carbonate was directly dried overnight in a NMR tube caped with a septum, under vacuum. $0.5 \mathrm{~mL}$ of dried DMSO-d6 and $12.5 \mu \mathrm{L}$ of TCB were added via the septum and the mixture was homogenized. The hexylamine (66 $\mu \mathrm{L}, 0.5 \mathrm{mmol}, 1$ eq.) was then added just before putting the tube in the NMR apparatus. The reaction was monitored with ${ }^{1} \mathrm{H}$ NMR spectroscopy with the disappearance of the cyclic carbonate protons for $24 \mathrm{~h}$.

- General procedure for polymerizations: PHUs were prepared from Und(ether)-bCC-S, Und(ester)-bCC-S, Oleyl(ether)-bCC-S, Trehal-Und-bCC-S and Trehal-Oleyl-bCC-S with 1,10diaminodecane (10DA), isophorone diamine (IPDA) and Priamine as comonomers with a molar ratio $1: 1$. PHU syntheses were performed in DMF $\left(1 \mathrm{~mol} \cdot \mathrm{L}^{-1}\right)$ at $70^{\circ} \mathrm{C}$ into a schlenk tube under magnetic stirring and nitrogen atmosphere for 7 days. No catalysts were added for the polymerization reactions. Conversions were determined by ${ }^{1} \mathrm{H}$ NMR spectroscopy after $24 \mathrm{~h}$ and 7 days of polymerization. 
- General procedure for sulfonation: 1 eq. of sulphur-activated cyclic carbonate was reacted with 3 eq. of m-chloroperbenzoic acid (mCPBA) per sulphur atom in DCM (1 g /20 mL) during $24 \mathrm{~h}$ at room temperature. The reaction mixture was then cooled up at $0^{\circ} \mathrm{C}$ to ensure the precipitation in DCM of the acidic form of mCPBA that was subsequently filtrated. The resulting organic phase was washed 4 times with $\mathrm{Na}_{2} \mathrm{SO}_{3}$ saturated solution, three times with $\mathrm{NaHCO}_{3}$ saturated solution and rinsed with deionized water in order to remove residual mCPBA. The organic phase was dried over magnesium sulphate and reconcentrated using rotary evaporator. No further purification was required. This procedure was applied to PHU post-functionalization. In the case of glycolipid-based PHU, the sulfonation was conducted in DMF and the purification was realized by dialysis in water in order to precipitate the polysulfone and to remove DMF, mcpba and its corresponding acidic form.

PHU 5-sulfone: IR ( $\left.\mathrm{cm}^{-1}\right)$ : 3328, 2919, 2850, 1725, 1687, 1534, 1387, 1281, 1247, 1117, 1127 , $1048,1009$. 


\section{Supporting Information}

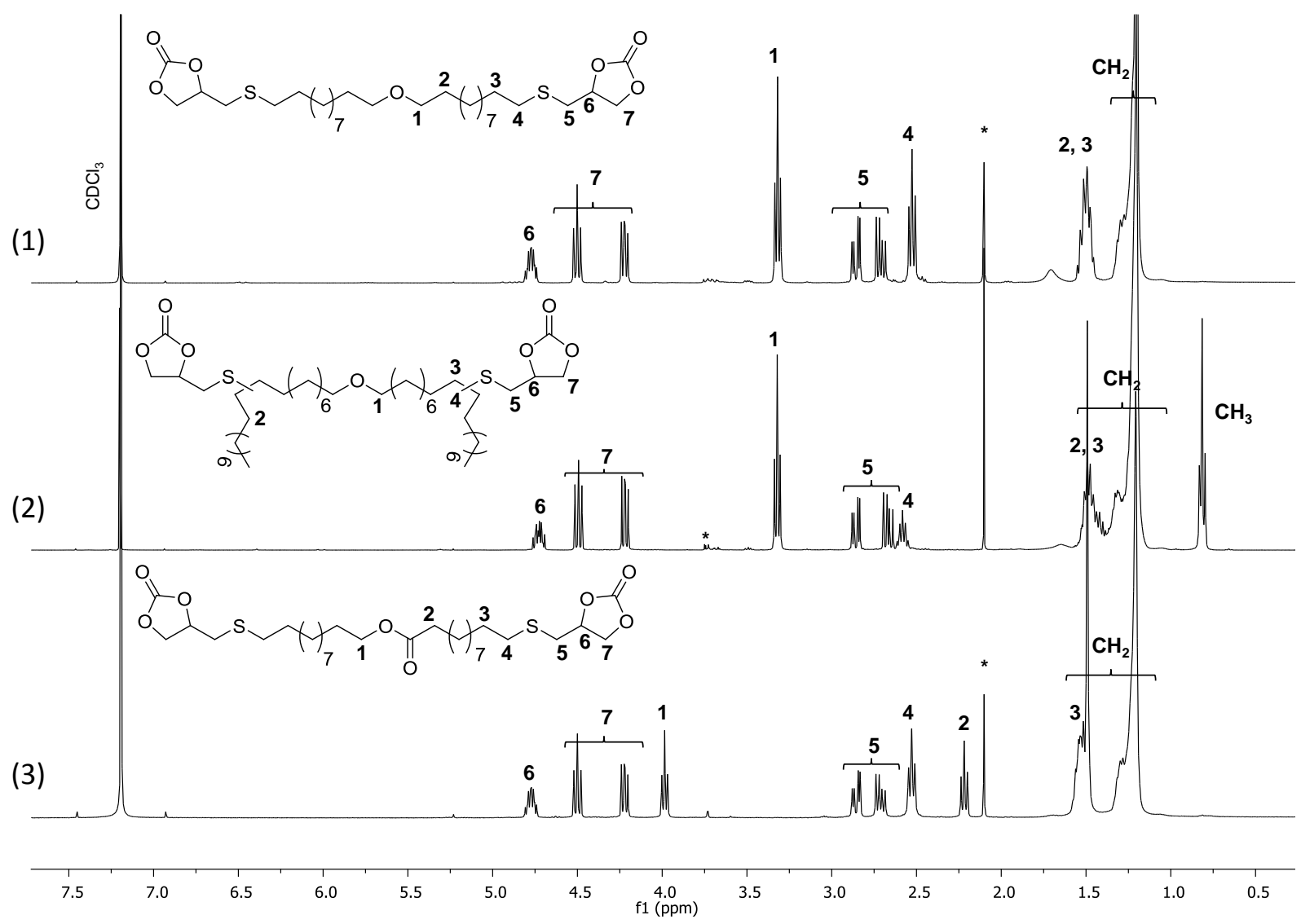

ESI Figure 1 - Stacked ${ }^{1} \mathrm{H}$ NMR spectra of (1) Und(ether)-bCC-S in $\mathrm{CDCl}_{3}(2)$ Und(ester)-bCC-S in $\mathrm{CDCl}_{3}$ and (3) Oleyl(ether)-bCC-S in $\mathrm{CDCl}_{3}(*$ impurities or solvent traces). 


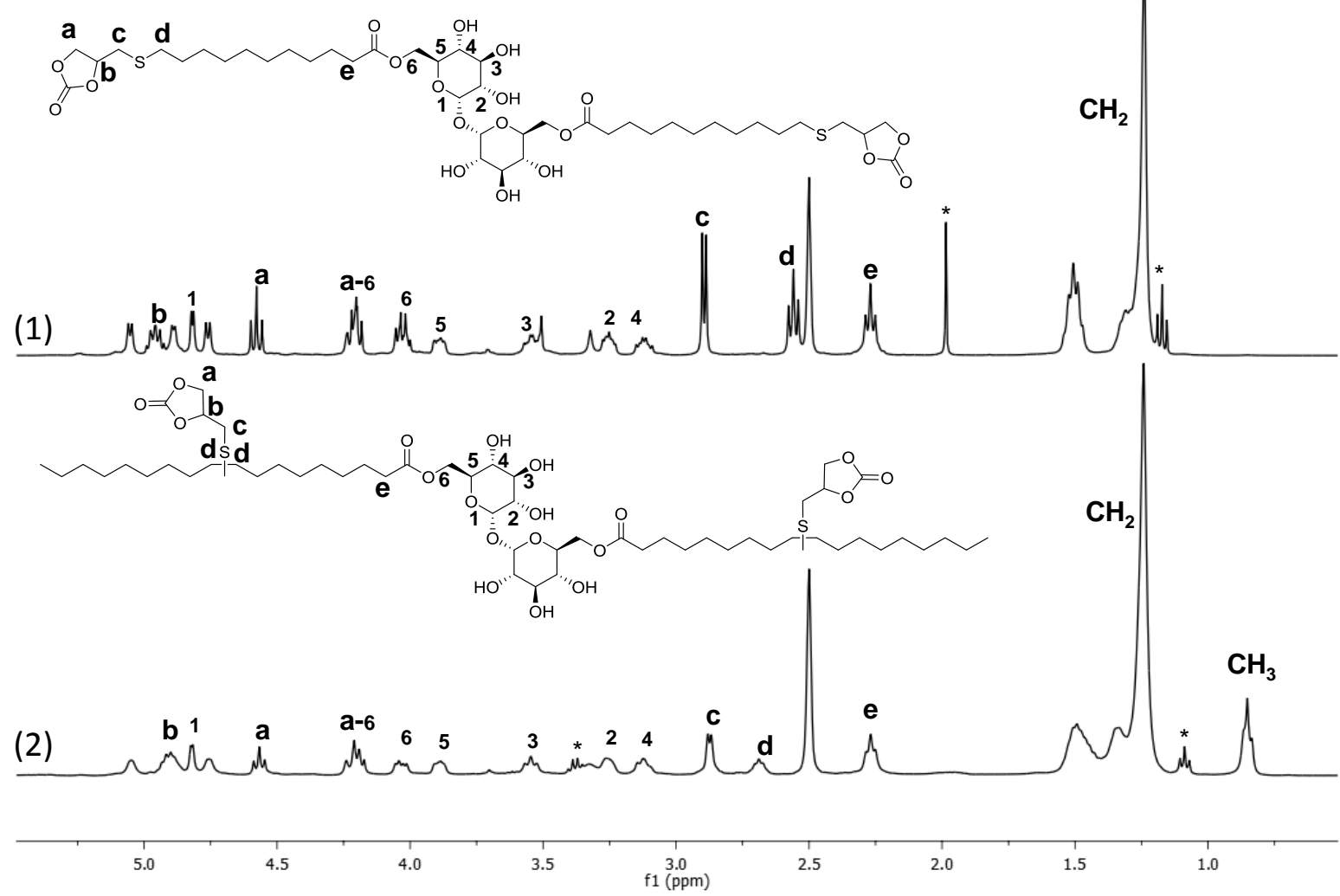

ESI Figure 2 - Stacked ${ }^{1}$ H NMR spectra of (1) Trehal-Und-bCC-S and (2)Trehal-Oleyl-bCC-S in DMSO-d 6 (*) Impurities. 

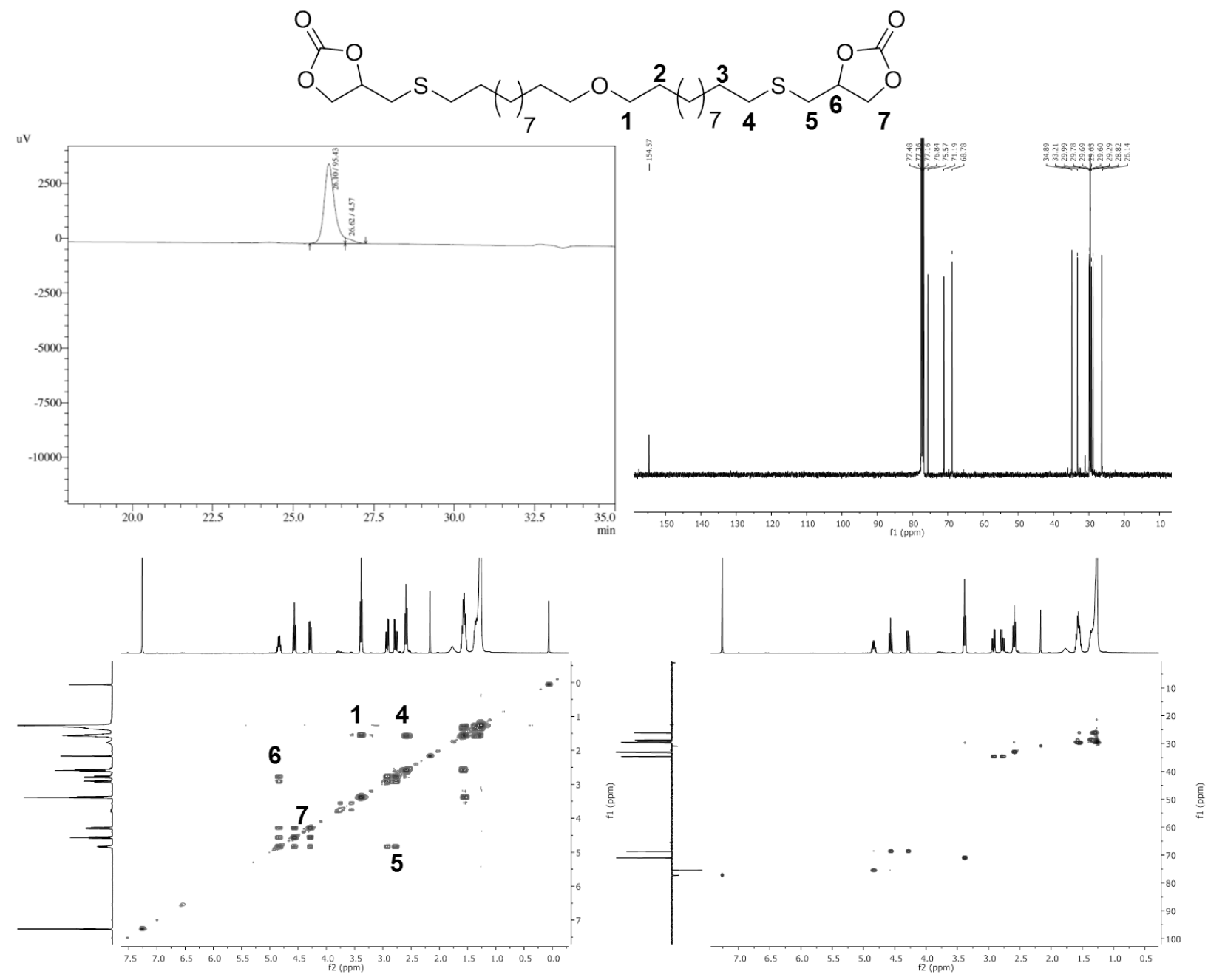

Figure ESI 3 - Characterization of Und(ether)-bCC-S (1) HPLC (95.4\% purity), (2) ${ }^{13} \mathrm{C}$ NMR, (3) ${ }^{1} \mathrm{H}-{ }^{1} \mathrm{H}$ COSY NMR and (4) ${ }^{1} \mathrm{H}^{13} \mathrm{C}$ HSQC-NMR (Analysis performed in $\mathrm{CDCl}_{3}$ ). 


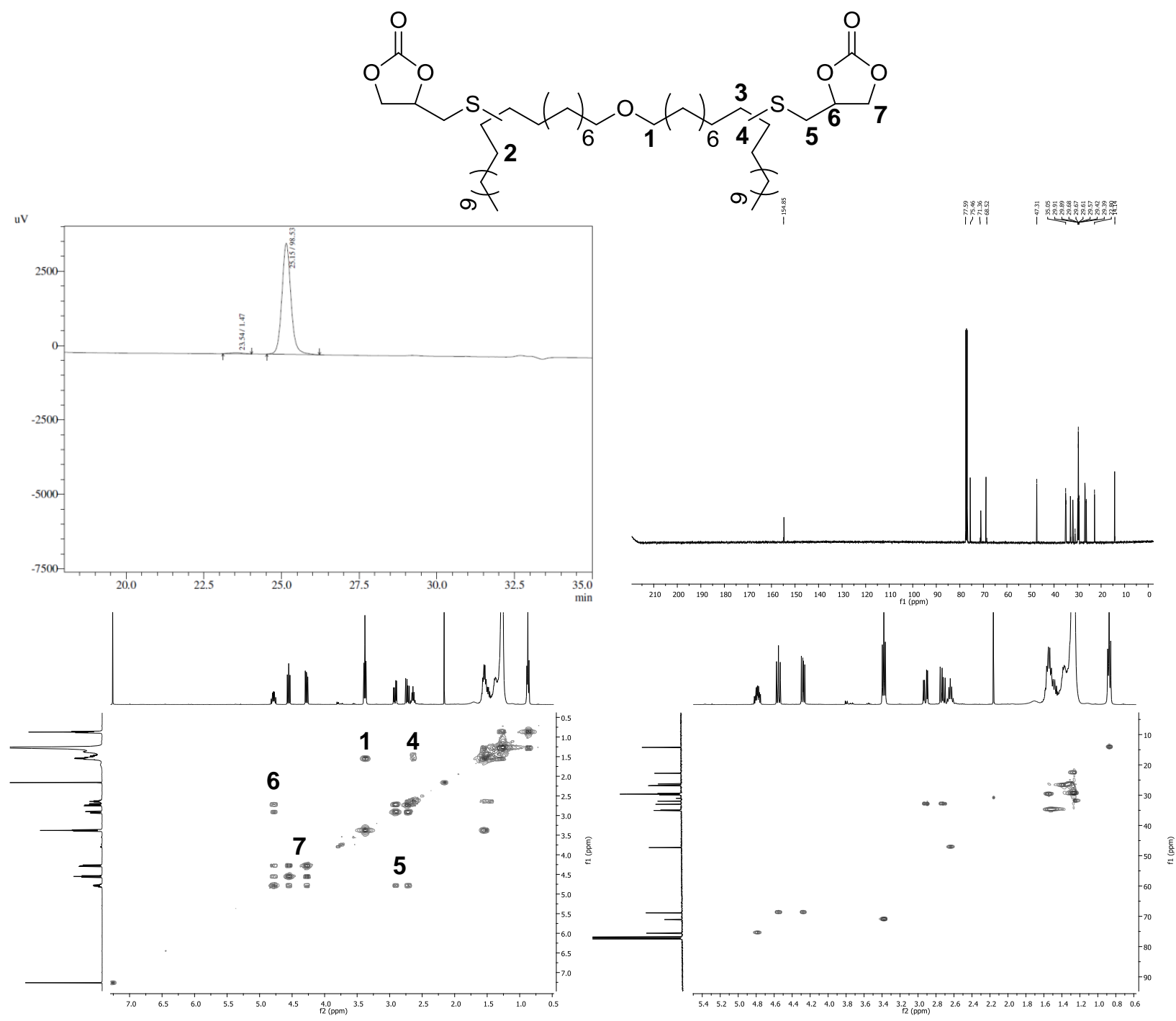

Figure ESI 4 - Characterization of Oleyl(ether)-bCC-S (1) HPLC (98.5\% purity), (2) ${ }^{13} \mathrm{C}$ NMR, (3) ${ }^{1} \mathrm{H}-{ }^{1} \mathrm{H}$ COSY NMR and (4) ${ }^{1} \mathrm{H}^{13} \mathrm{C}$ HSQC-NMR (Analysis performed in $\mathrm{CDCl}_{3}$ ). 


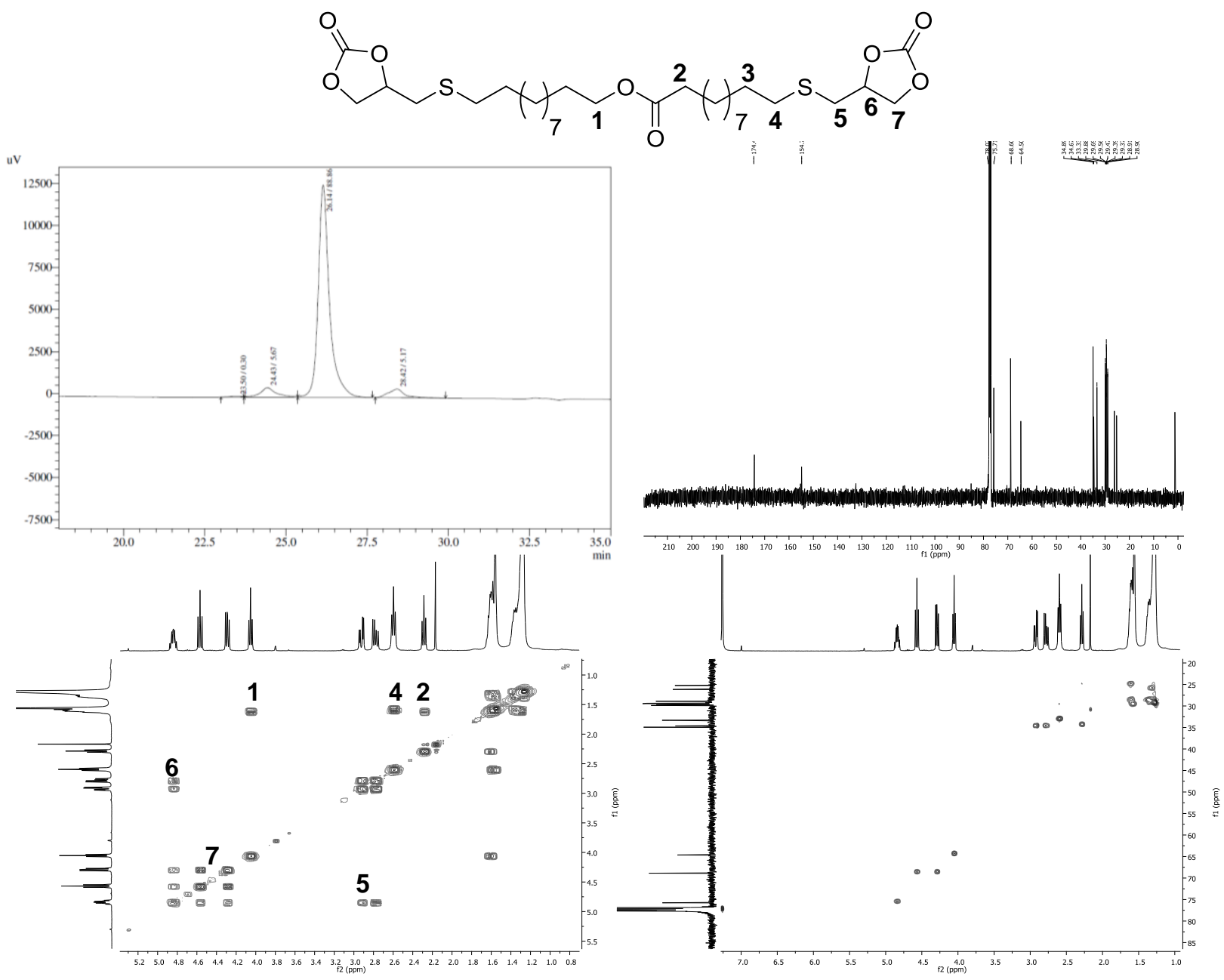

Figure ESI 5 - Characterization of Und(ester)-bCC-S (1) HPLC (88.9\% purity), (2) ${ }^{13} \mathrm{C}$ NMR, (3) ${ }^{1} \mathrm{H}-{ }^{1} \mathrm{H}$ COSY NMR and (4) ${ }^{1} \mathrm{H}-{ }^{13} \mathrm{C}$ HSQC-NMR (Analysis performed in $\mathrm{CDCl}_{3}$ ). 


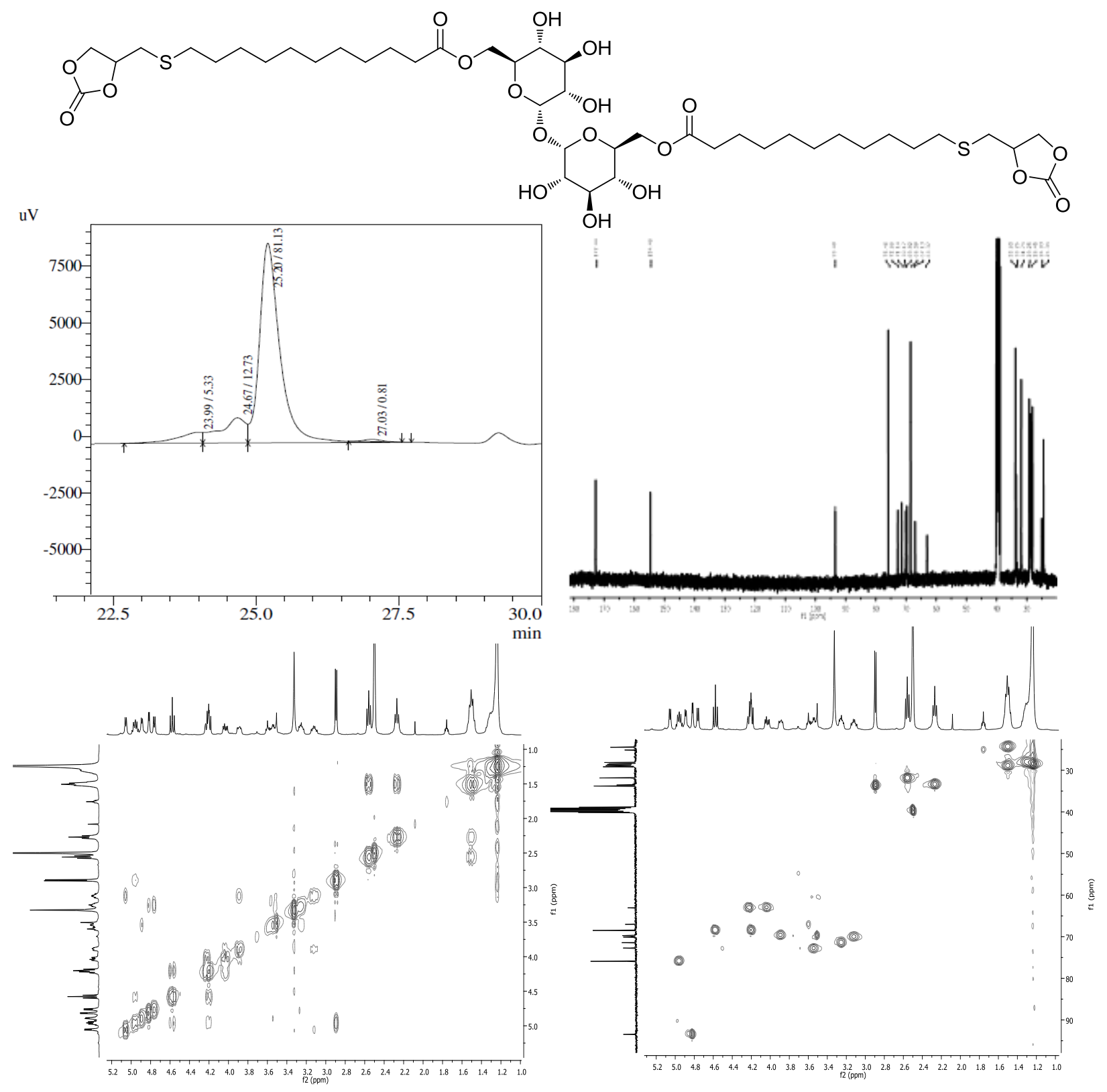

Figure ESI 6 - Characterization of Trehal-Und-bCC-S: (1) HPLC (81.1\% purity), (2) ${ }^{13} \mathrm{C} \mathrm{NMR,} \mathrm{(3)}{ }^{1} \mathrm{H}-{ }^{1} \mathrm{H}$ COSY NMR and (4) ${ }^{1} \mathrm{H}-{ }^{13} \mathrm{C}$ HSQC-NMR (Analysis performed in $\mathrm{CDCl}_{3}$ ). 


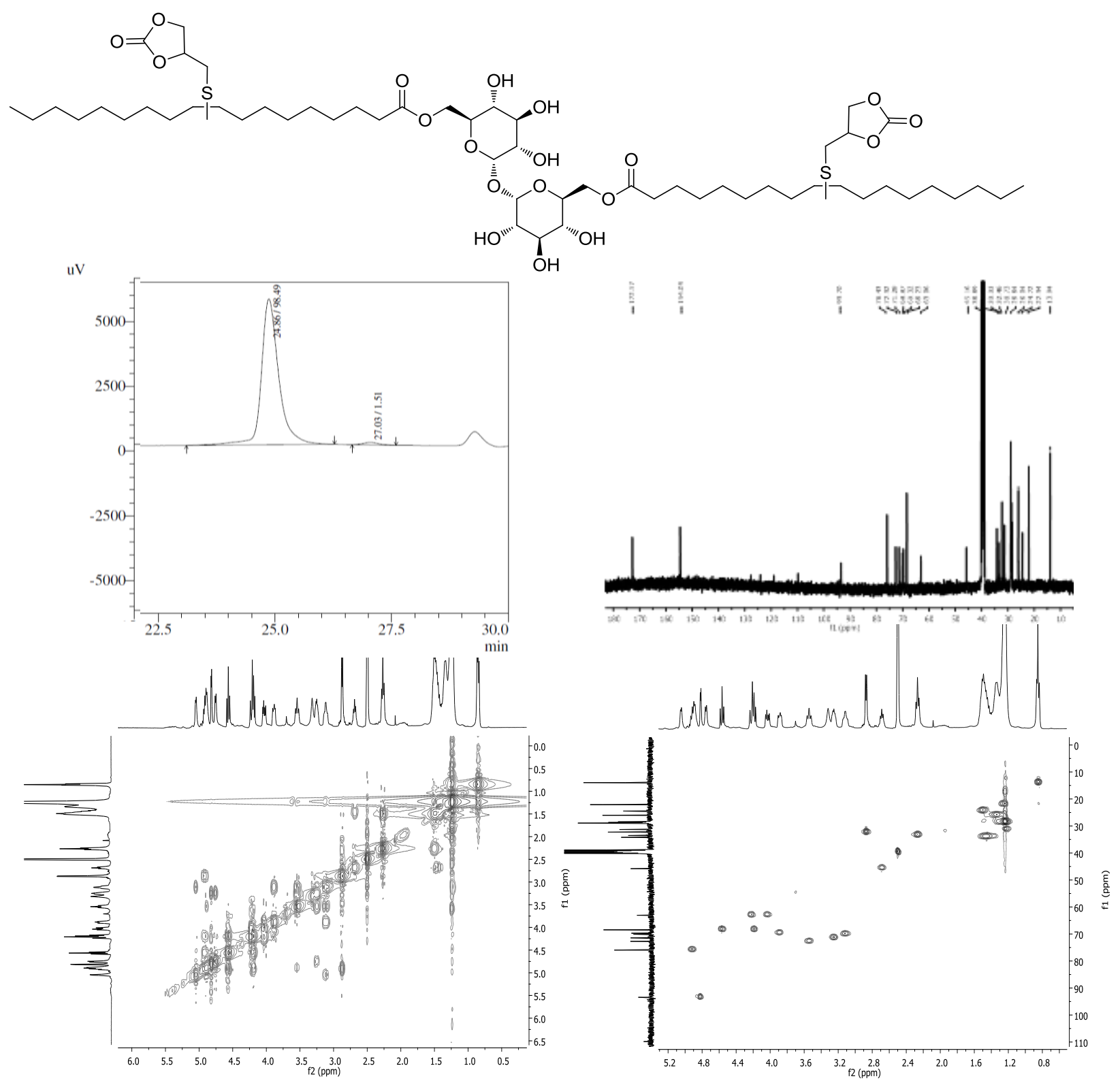

Figure ESI 7 - Characterization of Trehal-Oleyl-bCC-S: (1) HPLC (98.5\% purity), (2) ${ }^{13} \mathrm{C}$ NMR, (3) ${ }^{1} \mathrm{H}-{ }^{1} \mathrm{H}$ COSY NMR and (4) ${ }^{1} \mathrm{H}^{13} \mathrm{C}$ HSQC-NMR (Analysis performed in $\mathrm{CDCl}_{3}$ ). 
(1)
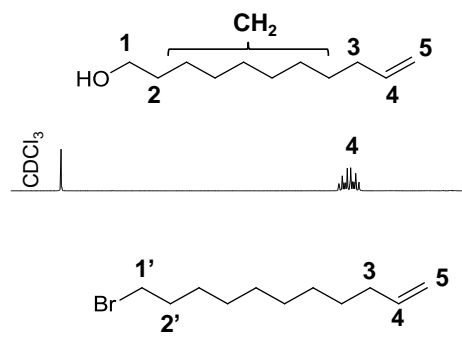

(2)

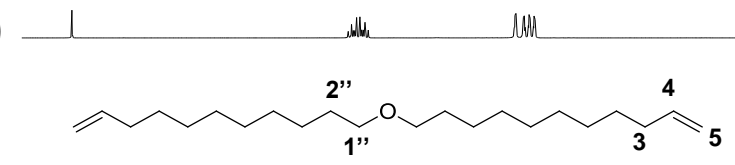

(3)

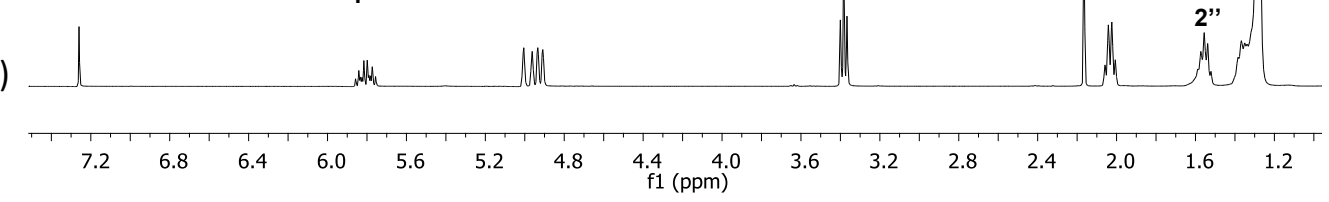

ESI Figure 8 - Stacked ${ }^{1}$ H NMR spectra of (1) 10-undecen-1-ol, (2) 1-bromo-10-undecene and (3) Und(ether)diene in $\mathrm{CDCl}_{3}(*)$ Impurities.

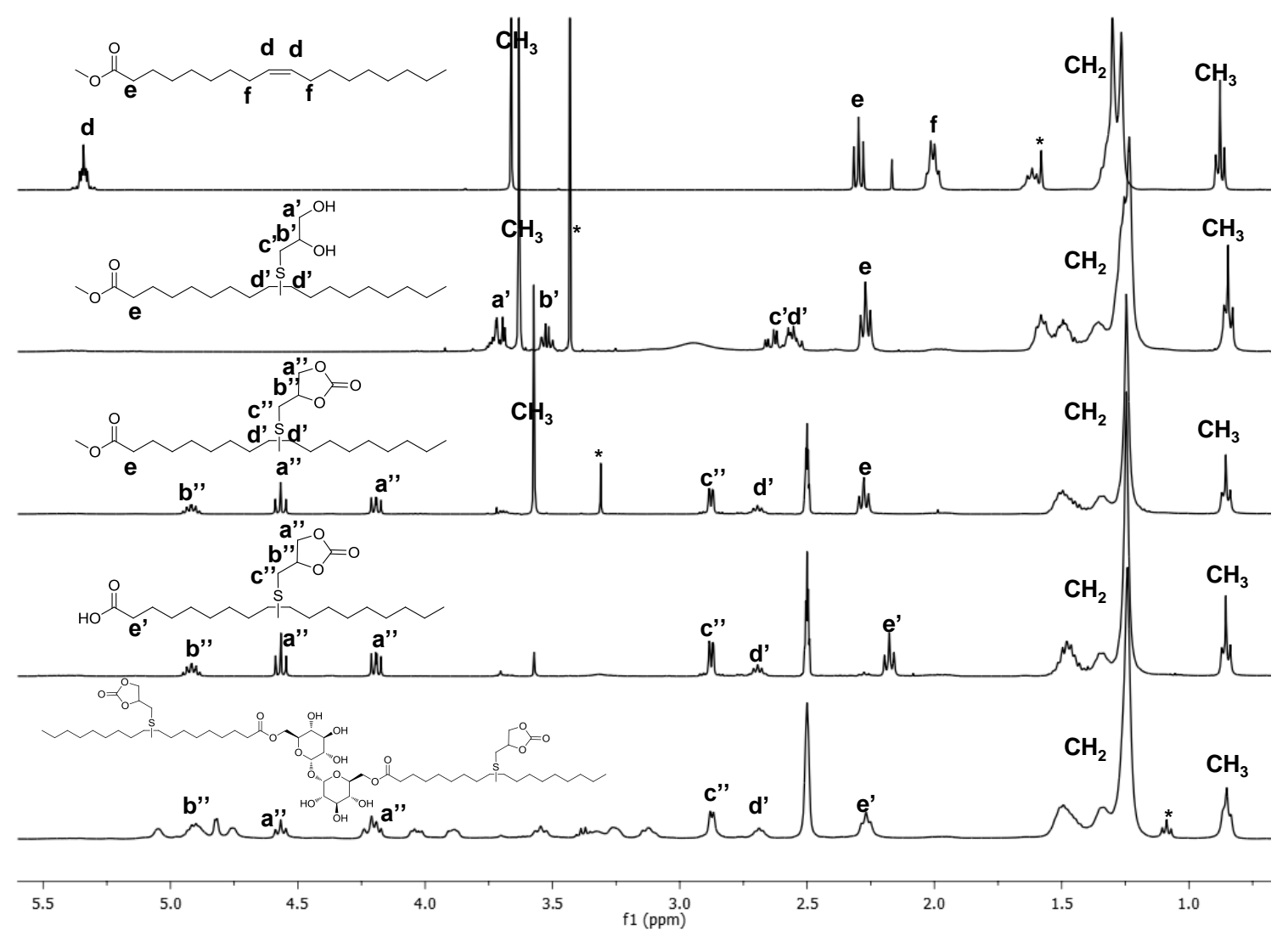

ESI Figure 9- Stacked ${ }^{1}$ H NMR spectra of intermediates of Trehal-Oleyl-bCC-S (*) Impurities. 


$$
\begin{gathered}
-\frac{d[C C]}{d t}=k_{a p p}[C C][A]=k_{a p p}[C C]^{2} \\
-\frac{d[C C]}{[C C]^{2}}=k_{a p p} d t \\
\frac{1}{[C C]}-\frac{1}{C_{0}}=k_{a p p} \Delta t \\
\text { or }[C C]=C_{0}-C_{0} x=C_{0}(1-x) \\
\frac{x}{1-x}=k_{a p p} C_{0} \Delta t
\end{gathered}
$$

ESI Formula $1-2^{\text {nd }}$ order Kinetic law formula: Time-(x/(1-x))

$$
\begin{gathered}
\% \text { Urea }=\frac{\int \boldsymbol{H}_{\text {urea }}}{\int \boldsymbol{H}_{\text {urea }}+\int \boldsymbol{H}_{\text {amide }}+\int \boldsymbol{H}_{\text {urethane }}} \\
\% \text { Amide }=\frac{\int \boldsymbol{H}_{\text {amide }}}{\int \boldsymbol{H}_{\text {urea }}+\int \boldsymbol{H}_{\text {amide }}+\int \boldsymbol{H}_{\text {urethane }}} \\
\% \text { Urethane }=\frac{\int \boldsymbol{H}_{\text {urethane }}}{\int \boldsymbol{H}_{\text {urea }}+\int \boldsymbol{H}_{\text {amide }}+\int \boldsymbol{H}_{\text {urethane }}}
\end{gathered}
$$

ESI Formula 2 - Formula used for the calculation of \% of urea, amide and urethane formed during kinetic measurements and polymerization, using ${ }^{1} \mathbf{H}$ NMR integrations of labile protons ( $\mathbf{H}_{\text {urea }}, \mathbf{H}_{\text {amide }}$ and $\mathbf{H}_{\text {urethane }}$ ) in DMSO-d6 . 


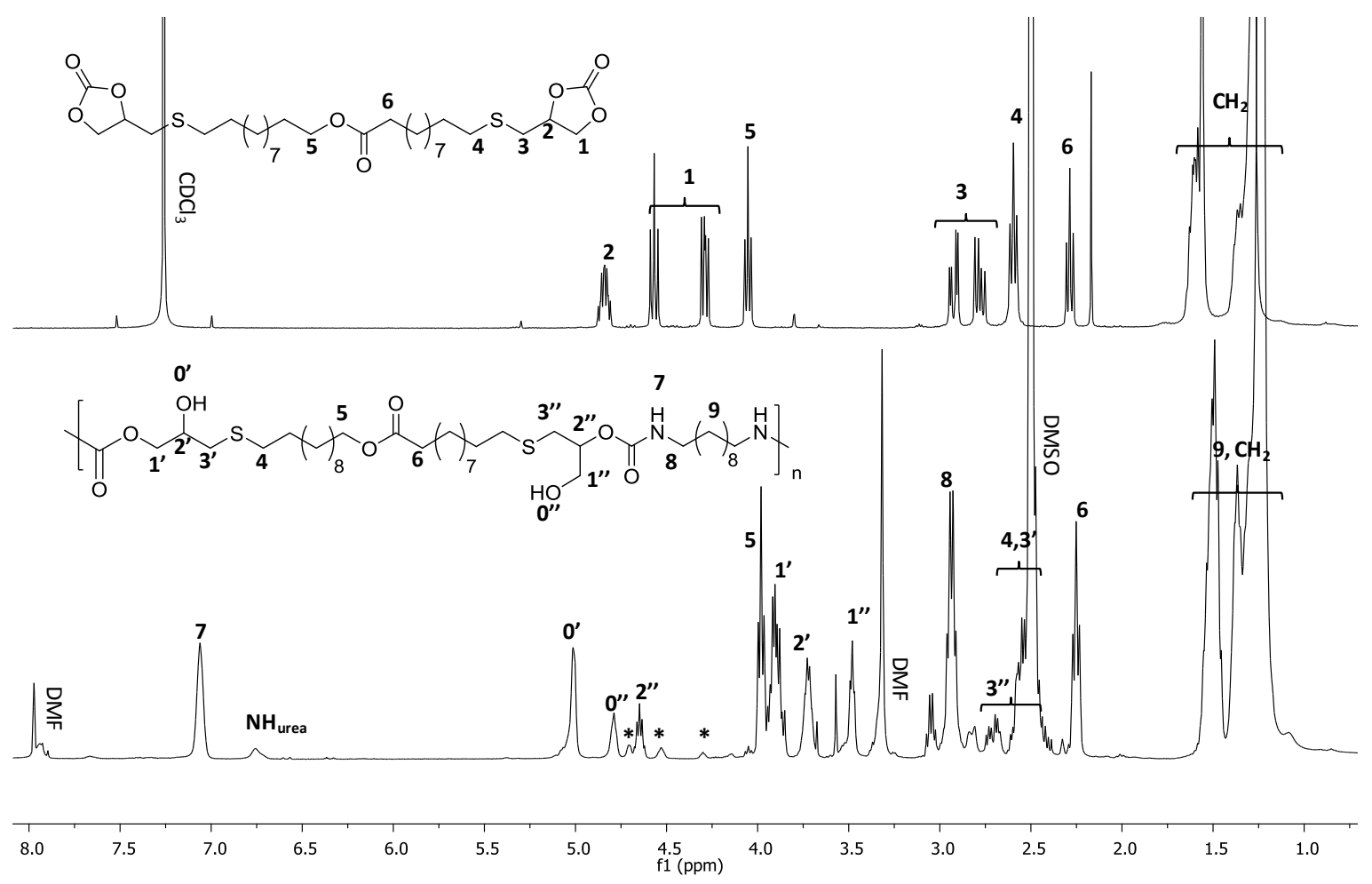

ESI Figure 10 - Stacked ${ }^{1} \mathrm{H}$ NMR spectra of (1) Und(ester)-bCC-S in $\mathrm{CDCl}_{3}$ and (2) PHU 5 in DMSO-d6. (* residual monomers/chain ends).
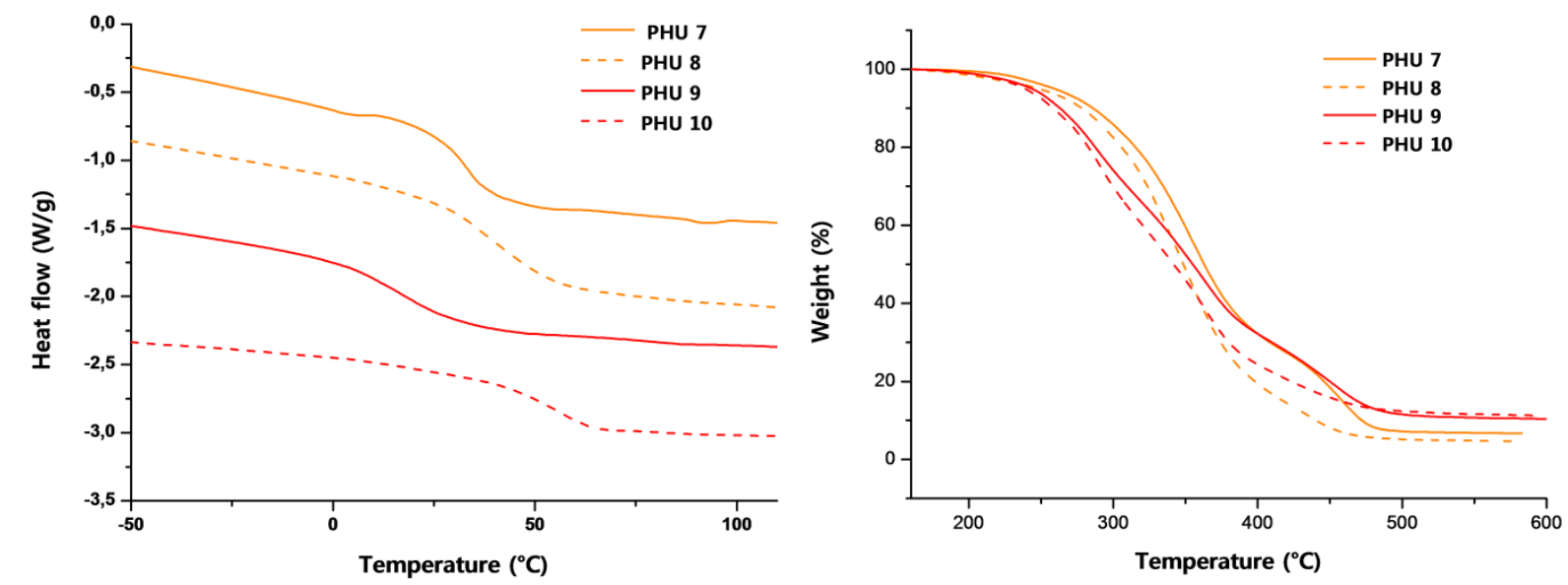

ESI Figure 11 - DSC second heating cycles $\left(10^{\circ} \mathrm{C} / \mathrm{min}\right)$ PHU 7 to PHU 10 and corresponding TGA traces from 160 to $600{ }^{\circ} \mathrm{C}$ (after an isothermal procedure of $15 \mathrm{~min}$ at $160^{\circ} \mathrm{C}$ to remove the residual DMF). 

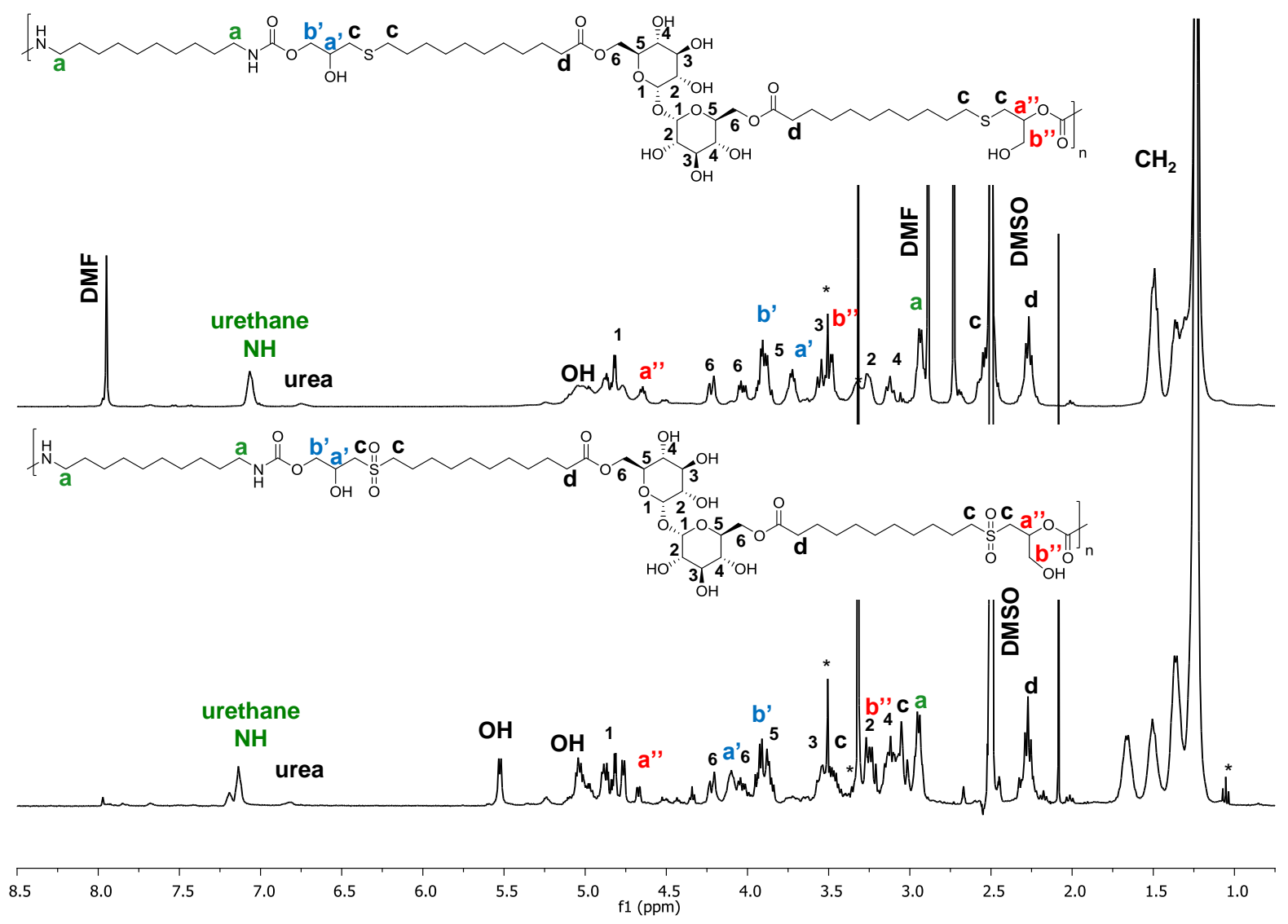

ESI Figure 12 - Stacked ${ }^{1}$ H NMR spectra of (1) PHU 7 and (2) PHU 7 -sulfone in DMSO-d6. (* residual monomers/chain ends). 